\title{
Autophagy induction as a therapeutic strategy for neurodegenerative diseases
}

Alvin Djajadikerta ${ }^{1,2,{ }^{*}}$, Swati Keshri ${ }^{1,2,{ }^{*}}$, Mariana Pavel ${ }^{3,{ }^{*}}$, Ryan Prestil ${ }^{1,2,{ }^{*},}$, Laura Ryan $^{1,2,{ }^{*}, \text { David C. Rubinsztein }}{ }^{1,2, \#}$

1 Department of Medical Genetics, and ${ }^{2}$ UK Dementia Research Institute, Cambridge Institute for Medical Research (CIMR), University of Cambridge, Cambridge, UK, ${ }^{3}$ Department of Immunology, "Grigore T. Popa” University of Medicine and Pharmacy, lasi, 700115, Romania.

*Joint first authors

\# Corresponding author. E-mail: dcr1000@cam.ac.uk

\section{Research highlights:}

- Autophagy delivers cytoplasmic cargoes to lysosomes for degradation

- It degrades many aggregate-prone proteins responsible for neurodegenerative disease

- Enhancing autophagy has therapeutic potential in common neurodegenerative diseases

- Evidence in cells and in vivo demonstrates promising results in many disease models

- Outcomes may depend on how autophagy impacts disease pathogenesis 


\section{Abstract}

Autophagy is a major, conserved cellular pathway by which cells deliver cytoplasmic contents to lysosomes for degradation. Genetic studies have revealed extensive links between autophagy and neurodegenerative disease, and disruptions to autophagy may contribute to pathology in some cases. Autophagy degrades many of the toxic, aggregate-prone proteins responsible for disease, including mutant huntingtin (mHTT), alpha-synuclein ( $\alpha$-syn), tau and others, raising the possibility that autophagy upregulation may help to reduce levels of toxic protein species and thereby alleviate disease. This review examines autophagy induction as a potential therapy in several neurodegenerative diseases - Alzheimer's disease, Parkinson's disease, polyglutamine diseases, and amyotrophic lateral sclerosis. Evidence in cells and in vivo demonstrates promising results in many disease models, in which autophagy upregulation is able to reduce the levels of toxic proteins, ameliorate signs of disease, and delay disease progression. However, effective therapeutic use of autophagy induction requires a detailed knowledge of how the disease affects the autophagy-lysosome pathway, as activating autophagy when the pathway cannot go to completion (e.g. when lysosomal degradation is impaired) may instead exacerbate disease in some cases. Investigating the interactions between autophagy and disease pathogenesis is thus a critical area for further research.

Keywords: lysosome, Alzheimer's disease, Parkinson's disease, polyglutamine diseases, amyotrophic lateral sclerosis 


\section{Introduction}

Macroautophagy (henceforth referred to as autophagy) is a major, conserved cellular process by which cells deliver cytoplasmic contents to lysosomes for degradation. This transport involves delivery of these contents by double-membraned vesicles called autophagosomes, in contrast with other pathways, like chaperone-mediated autophagy (CMA) and microautophagy, which do not involve vesicular transport. While autophagy was initially characterised as a primordial, non-selective degradation pathway induced to counteract nutrient deprivation, it has become increasingly clear that autophagy plays a key role in the homeostasis of non-starved cells. Critically, autophagy appears to degrade aggregate-prone proteins, damaged mitochondria, and invading pathogens, and these functions appear to be linked to a range of human disease ${ }^{1,2}$.

One area of particular interest is the relevance of autophagy to neurodegenerative diseases. Many neurodegenerative diseases, including Alzheimer's disease, Parkinson's disease, and Huntington's disease, arise from the accumulation of oligomers and aggregates of misfolded proteins. As these proteins exert toxic effects on cells, lowering the levels of these proteins can be therapeutically favourable ${ }^{1}$. Autophagy degrades many of the toxic aggregate-prone proteins responsible for disease, including mutant huntingtin (mHTT), alpha-synuclein ( $\alpha$-syn), tau and others ${ }^{3-5}$. Many of these proteins also cause disruptions in autophagy ${ }^{6,7}$, raising the possibility that their ability to hinder autophagy contributes to their toxicity. In further support of a relationship between autophagy and neurodegenerative disease, some risk genes linked to neurodegenerative diseases play a role in the autophagy pathway ${ }^{1,8}$. This considerable body of evidence linking autophagy and neurodegeneration gives rise to the possibility that autophagy upregulation may be a viable therapeutic strategy in some neurodegenerative diseases. 
Understanding the interplay between autophagy and neurodegeneration requires a knowledge of the multiple steps and regulatory pathways involved in the autophagy pathway. The process of autophagy involves a series of regulated mechanical steps, including autophagosome formation, maturation and closure 2,9 . The initial stages of autophagy are marked by cup-shaped, double-membraned phagophores, the formation of which requires $\mathrm{PI}(3) \mathrm{P}$ generation by the Beclin-1-VPS34 complex ${ }^{10,11}$. The edges of these phagophores subsequently extend and fuse to form autophagosomes ${ }^{12}$. These are trafficked towards the proximity of lysosomes via the dynein machinery on microtubules ${ }^{13}$, which allows fusion with lysosomes and degradation of autophagosomal contents. Each of these steps is subject to regulation by various upstream signalling pathways, notably via mTORC1, a major regulator of cell metabolism, ${ }^{14}$ and TFEB ${ }^{15}$, a key transcriptional regulator of autophagy and lysosomal biogenesis. Autophagic flux thus depends on multiple steps and requires coordination between autophagosome biogenesis and lysosomal degradation. Interventions aimed at inducing autophagy have been targeted towards various stages in this process, potentially leading to different effects on disease progression.

This review will focus primarily on the potential of autophagy upregulation as a therapeutic strategy in several classes of neurodegenerative disease: Alzheimer's disease (AD) and tauopathies, Parkinson's disease (PD), polyglutamine diseases, and amyotrophic lateral sclerosis (ALS). Although most instances of neurodegenerative disease are sporadic, a small number of cases in each disease have been associated with disease-causing mutations in critical genes. These cases have allowed for the generation of important insights into the pathogenesis of each disease and are used in many of the cell and animal models of each illness. In each section, we briefly explore how proteins linked to the relevant disease impact autophagy. Subsequently, we describe the evidence in cells and in vivo models on whether autophagy induction may be of therapeutic value. Thorough reviews have previously been published on the pathogenesis of each of the described neurodegenerative diseases ${ }^{16-19}$ and on the cell biology of autophagy ${ }^{1,2}$, so these will not be explored in detail here. 


\section{Alzheimer's disease and tauopathies}

$A D$ is a neurodegenerative disease clinically characterized by progressive dementia and cognitive impairment. The pathology of $A D$ is defined by the presence of two main hallmark elements: intracellular accumulation of neurofibrillary tangles (formed of hyperphosphorylated tau, a microtubule associated protein) and extracellular deposits of amyloid- $\beta(A \beta)$ plaques arising from defective amyloid precursor protein (APP) processing. AD is the most common of the tauopathies, a class of neurodegenerative diseases characterised by pathological tau aggregation, including neuronal disorders such as frontotemporal dementias (FTDs), corticobasal degeneration (CBD), progressive supranuclear palsy (PSP), and primary agerelated tauopathy (PART) $)^{1,20,21}$.

\section{Defective autophagy in AD}

Autophagy plays a crucial role in continuously maintaining the homeostatic turnover of diffuse cytosolic proteins in neurons. Therefore, decreased autophagic flux results in impaired neuronal function and defects at different steps of the autophagy pathway may explain the pathology seen in $A D$ and various tauopathies. While autophagy dysfunction may not be the principal cause of neurodegeneration, it may contribute to disease progression and pathology as a consequence of impaired turnover of toxic substrates in neurons. Two main defects in autophagy have been implicated in the pathogenesis of $A D$ : impaired autophagosome synthesis $^{22}$ and reduced clearance of autophagic substrates ${ }^{8,22,23}$.

Decreased Beclin-1 levels result in reduced autophagic activity and have been associated with aging and neurodegeneration ${ }^{21,24}$. Affected brain regions from patients with $A D$ were shown to have decreased Beclin-1 mRNA expression and protein levels, which may explain the reduced autophagosome formation correlated with this disease ${ }^{22}$. Beclin-1 protein levels may be additionally decreased as a consequence of caspase 3 activation in the brain of $A D$ patients ${ }^{25}$. Recent studies also identified reduced expression of the chaperonin CCT/TRiC complex in $\mathrm{AD}$ patient brain samples ${ }^{26,27}$. Apart from acting as a chaperone for tau (assisting 
its proper folding), CCT is essential for optimal autophagy-lysosomal activity by maintaining the physiological cell cytoskeleton structure in mouse primary neurons ${ }^{27}$. When CCT activity is impaired, the consequent reduction in autophagy flux results in accumulation of aggregateprone proteins such as p62, Ataxin-3 or $\mathrm{mHTT}^{27}$.

Genome-wide association studies identified risk loci and variants in PICALM to be associated with Alzheimer' disease, and biochemical assessment of $A D$ patient brains showed accelerated cleavage and consequent loss of function of PICALM ${ }^{28,29}$. PICALM depletion impairs the endocytosis of VAMP2 and VAMP3 (SNAREs involved in the fusion of autophagosome precursors) as well as VAMP8 (involved in autophagosome-lysosome/late endosome fusion events) ${ }^{30}$. This consequently reduces both autophagosome biogenesis and fusion with lysosomes, leading to tau accumulation ${ }^{8,30}$.

Mutations of presenilin-1 (PS1) cause early-onset familial Alzheimer's disease, and there is substantial evidence showing that these mutations impair autophagosome degradation via lysosomal V-ATPase dysfunction in patient-derived cells ${ }^{31}$. Apart from being part of the $\gamma^{-}$ secretase complex and functioning in A cleavage, PS1 acts as an ER chaperone for the VATPase subunit VoA1 required for lysosomal acidification and autophagic turnover ${ }^{31}$. Abnormally increased levels of acid sphingomyelinase in the brains and fibroblasts of $A D$ patients result in reduced TFEB levels due to proteolysis ${ }^{32}$. Chemical inhibition of this enzyme with amitriptyline in an APP/PS1 mouse model of AD improved autophagosome turnover and delayed disease development ${ }^{8}, 32$. In addition, several genetic risk factors for $A D$, such as the APOE4 variant and pathogenic mutations or duplication of APP, have been found to upregulate Rab5 and endocytosis ${ }^{23,33-36}$. This causes overloading of the swollen lysosomes with proteins and lipids and reduced clearance of autophagic cargo. Indeed, AD mouse models show accumulation of autophagy substrates, due to lysosomal dysfunction ${ }^{37,38}$. 


\section{Autophagy inducers in Alzheimer's disease}

The significant evidence linking autophagy and tauopathies has generated interest in developing autophagy-based therapeutics, and studies so far have indicated promising therapeutic potential in Alzheimer's disease and various tauopathies ${ }^{5,39,40}$. Autophagy stimulation may be performed either chemically using small molecule enhancers of autophagy or through gene therapy approaches. Here we will summarise the results reported in different models of various autophagy-enhancing therapeutics.

Small molecule enhancers of autophagy may be split in two main categories based on their mechanism of action: mTOR-dependent or mTOR-independent ${ }^{1,21,39}$. The first category of autophagy-inducing compounds is composed of mTOR inhibitors, including rapamycin and other rapalogs. These compounds were shown to provide beneficial effects in animal models of $A D$ and other neurodegenerative tauopathies ${ }^{1}$. More specifically, both rapamycin and temsirolimus (a rapalog) enhanced the neuronal autophagic clearance of hyperphosphorylated tau and consequently rescued the spatial learning and memory impairments in P301S mutant tau transgenic mice ${ }^{41,42}$. Similarly, long-term reductions in mTOR signalling lowered the levels of $A \beta$ and improved cognitive function in the well-defined transgenic PDAPP mouse model of $A D^{43}$. Rapamycin also reduced toxicity and increased survival to adulthood in Drosophila expressing wild-type or mutant variants of tau (R406W), effects accounted for by an autophagy-dependent reduction in insoluble tau levels ${ }^{44}$. Indeed, treatment with rapamycin or other rapalogs decreased only the insoluble form of tau in COS7 cells expressing the most common tau mutation (P301L), or SH-SY5Y cells incubated with okadaic acid $^{41,44}$.

The second group of chemical compounds enhances autophagy independently of mTOR and comprises a continuously expanding list of molecules. One of those molecules, trehalose, a naturally occurring disaccharide that acts as a "chaperone" by assisting proper protein folding through direct protein-trehalose interactions, has been shown to induce autophagy through AMPK activation caused by its inhibitory effect on the SLC2A family of glucose transporters 
(also known as GLUT) ${ }^{45-47}$. Trehalose treatment enhanced the clearance of tau aggregates and reversed the dropout of dopamine neurons in an autophagy-dependent manner in several transgenic in vivo models of tauopathies, including a mouse model expressing the human mutant P301S tau and a mouse model of tau overexpression with Parkinsonism ${ }^{5,48}$. Interestingly, pharmacological doses of melatonin, a neurohormone that activates AMPK, were recently reported to restore autophagy flux and prevent cognitive decline in mouse models of tauopathies ${ }^{49}$. Another small neuroprotective peptide, humanin, identified initially from a cDNA library of $A D$ patients ${ }^{50}$, is able to decrease $A \beta$ deposition in the brain of APP/PS1 transgenic mice in an autophagy-dependent fashion ${ }^{51}$. Activation of autophagy by humanin occurs via reducing neuronal insulin resistance via IRS-1 signalling inhibition and AMPK activation.

Other AMPK modulators, such as metformin, nilotinib or bosutinib, have been reported to have beneficial effects in the transgenic APPswe/PS1 $\triangle \mathrm{E} 9^{52}$ and TgAPP mouse models ${ }^{53,54}$. Early results from pilot clinical trials of metformin in $A D$ appear promising, although they require further validation from larger studies. One randomised placebo-controlled trial of metformin in amnestic mild cognitive impairment $(\mathrm{aMCl})$ demonstrated a small beneficial effect on total memory recall ${ }^{55}$, and another crossover study demonstrated an association with improved executive functioning ${ }^{56}$. However, some studies have found that autophagy activation by metformin, nilotinib or bosutinib causes secretion of $A \beta$ into the extracellular space and promotes amyloidogenic APP processing by $\mathrm{Y}$-secretase in autophagosomes in Tg6799 mice $^{57}$ and Apoliprotein $\mathrm{E}$ deficient (ApoE-/-) mice ${ }^{58}$. Other pathways unrelated to protein clearance may thus important to consider when evaluating the potential efficacy of a therapy.

Another group of compounds known to upregulate autophagy and enhance clearance of autophagic substrates comprises a class of mood stabilizing drugs, including lithium ${ }^{46,59}$. Lithium administration impairs phosphoinositol signalling via cellular depletion of inositol by impairing $\mathrm{IP}_{3}$ recycling. Reduced $\mathrm{IP}_{3}$ levels lead to decreased levels of $\mathrm{Ca}^{2+}$ in the cytoplasm and decreased mitochondrial $\mathrm{Ca}^{2+}$ uptake, causing lower ATP production followed by 
activation of AMPK, which directly phosphorylates ULK1 and induces autophagy ${ }^{60}$. Lithium additionally upregulates autophagy by inhibiting GSK3 $\beta$ activity and reduces tau phosphorylation and amyloid production in pre-pathological AD mouse models (AßPPswe/PSA1A246E) ${ }^{61}$. Recent studies strengthen the relevance of the GSK3 $\beta$-autophagy axis in $A D$, as pharmacological inhibition of GSK3 $\beta$ (using the inhibitor SB216763) upregulates the expression of TFEB and other autophagy genes, and thereby restores lysosomal function in PS1-knockout or -mutant neurons ${ }^{62}$. Activation of other autophagy-related transcription factors, such as the nutrient-sensing nuclear receptors PPARa, with relevant agonists (gemfibrozil or Wy14643) increased $A \beta$ clearance and rescued the cognitive deficits in APP/PS1 $1 \mathrm{E} 9$ mice $^{63}$.

Initial data from clinical trials relating to the use of lithium in AD has revealed some promising results. One clinical trial investigating the efficacy of lithium as a neuroprotective agent in patients with AD-associated mild cognitive impairment reported positive findings, with lithiumtreated patients displaying reduced cognitive decline over a two-year period compared to the placebo group ${ }^{64}$. This attenuation of decline was associated with increased amyloid-beta peptide in the CSF, which may reflect clearance of $A \beta$ from the brain. It may be interesting to investigate this data in connection with the aforementioned $A \beta$ secretion into the extracellular space on some instances of autophagy induction ${ }^{57}$. Other clinical trials have shown no effects on disease markers ${ }^{65,66}$, although these negative findings may in part be due to the small sample sizes and short treatment durations used in these trials.

Multiple screens of FDA-approved drugs have identified new mTOR-independent modulators of autophagy, which include imidazoline receptor agonists, L-type $\mathrm{Ca}^{2+}$ channel antagonists and calpain inhibitors ${ }^{46,67}$. The first class of drugs is comprised of imidazoline receptor agonists such as clonidine and rilmenidine. While these drugs are extensively used as antihypertensive agents in humans with no significant side effects, they are also known to induce autophagy by decreasing intracellular cAMP levels ${ }^{67-69}$. The beneficial effects of clonidine and rilmenidine were tested on an experimental zebrafish model expressing the human $\mathrm{A} 152 \mathrm{~T}$ 
mutant tau coupled to the green-to-red photoswitchable fluorescent protein Dendra ${ }^{40}$. The rare p.A152T variant of tau is a genetic risk factor for the tauopathy progressive supranuclear palsy $(\mathrm{PSP})^{40,70}$. Indeed, treatment with either imidazoline receptor agonist increased the clearance of mutant tau and ameliorated the abnormal morphological and motor defects seen in untreated $\mathrm{A} 152 \mathrm{~T}$ tau fish ${ }^{40}$.

The second class of compounds, the L-type $\mathrm{Ca}^{2+}$ channel antagonists (felodipine and verapamil), block the influx of extracellular $\mathrm{Ca}^{2+}$ and thus decrease intracellular $\mathrm{Ca}^{2+}$ levels and mitochondrial $\mathrm{Ca}^{2+}$ uptake. This leads to lower ATP production followed by AMPK activation, which directly phosphorylates ULK1 and enhances autophagy in mouse primary neurons and in vivo models of tauopathies ${ }^{60,71}$. These two drugs were tested in two transgenic zebrafish models expressing either mutant A152T tau pan-neuronally or wild-type human tau in rod photoreceptors only ${ }^{71}$. Both drugs, via an autophagy-dependent mechanism, ameliorated the abnormal morphological phenotype and significantly reduced the levels of insoluble tau species in these fish models. Elevated levels of intracellular $\mathrm{Ca}^{2+}$ can also activate the $\mathrm{Ca}^{2+}$-dependent cysteine proteases (calpains), which impair autophagy. Chemical inhibition of calpains with calpastatin (the endogenous calpain inhibitor), calpeptin or genetic knockdown, has the opposite effect of stimulating autophagy ${ }^{67}$. Indeed, studies using the calpain inhibitor A-705253 showed beneficial effects in clearing $A \beta$ and hyperphosphorylated tau with improved cognition in transgenic 3xTg-AD mice harbouring mutations in three genes, PS1(M146V), APP(swe) and Tau(P301L) $)^{72}$.

\section{Genetic approaches in Alzheimer's disease}

The aforementioned pharmaceutical compounds offer clear evidence that autophagy upregulation is beneficial for $A D$ in in vivo models. However, one should account for their possible side effects when translating these potential therapeutic strategies in humans, as these chemicals likely have additional signalling targets independent of the autophagy pathway. One potential strategy to overcome these unwanted effects is the use of gene therapy approaches to induce expression of key autophagy genes. 
Lentiviral-induced Beclin-1 expression, one of the most common strategies to stimulate autophagy by gene therapy, was shown to reduce both intracellular and extracellular amyloid pathology in the hippocampus and cortex of APP transgenic mice 22 . An elegant approach using a knock-in point mutation F121A in Beclin-1, which prevents the Beclin-1 interaction with its inhibitor BCL2, led to hyperactivation of autophagy with a consequent significant decrease in $A \beta$ levels and restoration of survival in $5 x F A D$ mice (expressing a combination of five familial AD (FAD) mutations in human APP and PS1 genes) ${ }^{73}$. Beclin-1-mediated autophagy may also be stimulated by lentiviral Parkin transduction, promoting clearance of damaged mitochondria and intracellular $A \beta$ degradation in a triple transgenic $A D$ mouse model (3xTg-AD) expressing the PS1(M146V), APP(swe), Tau(P301L) and knock-in mutations ${ }^{74}$.

Overexpression of another essential autophagy gene, Atg5, induces autophagy and ameliorates the abnormal morphological defects in an A152T-tau zebrafish model ${ }^{40}$. Intriguingly, deletion of $A \operatorname{tg} 7$ in APP transgenic mice results in reduced A $\beta$ plaque deposition as a consequence of reduced $A \beta$ secretion into the extracellular space ${ }^{75}$. Similarly to pharmacological inhibition, knockdown of calpain or calpastatin overexpression are protective against tau toxicity in multiple in vivo models of tauopathies ${ }^{76,77}$.

For many tauopathies, upregulation of autophagy may be an attractive therapeutic strategy successful autophagy induction and improved neurodegeneration phenotypes were seen in various in vivo models ${ }^{1,39,78}$. However, diseases with impairment in the late stages of autophagy and lysosomal functioning may not benefit from further activation of autophagy. In these cases, overexpression of genes such as BECN1 and ATG5 that mainly induce autophagosome synthesis with little effect on lysosomal function may potentially only lead to unproductive accumulation of autophagosomes. A promising therapeutic approach for complex diseases like AD may be to enhance the overall autophagic flux by acting on different steps in the autophagy pathway. Therefore, an interesting target for drug development may be TFEB, which is known to be involved in both autophagosome formation and lysosomal 
biogenesis ${ }^{1}{ }^{15}$. Indeed, overexpression of TFEB was beneficial in reducing neurofibrillary tangles and restoring behavioural defects in a rTg4510 mouse model of tauopathy ${ }^{79}$. 


\section{Parkinson's Disease}

Parkinson's disease (PD) is a debilitating neurodegenerative disorder primarily characterised by progressive loss of motor control and, in many cases, cognitive decline. These symptoms are the result of the death of dopaminergic neurons in the substantia nigra pars compacta, and are associated with the accumulation of intraneuronal protein aggregates (Lewy bodies), predominantly comprised of $\alpha$-synuclein $(\alpha \text {-syn })^{80}$. A large body of evidence implicates defective autophagy as central to both the aetiology and pathogenesis of Parkinson's disease, and numerous genetic mutations encoding components of the autophagic machinery or relevant to the autophagy-lysosomal pathway (ALP) have been identified as disease risk factors $^{81,82}$. Both autophagosome biogenesis and autophagosome-lysosome fusion appear to be compromised in PD neurons ${ }^{81}$, and so induction of macroautophagy has received much attention as a therapeutic strategy to ameliorate the toxic effects of $\alpha$-syn accumulation.

A wealth of research implicates the intrinsically disordered protein $\alpha$-syn as a significant contributor to autophagic deregulation and PD pathogenesis. Overexpression of $\alpha$-syn is sufficient to induce the accumulation of filamentous protein inclusions, the death of dopaminergic neurons, and locomotor abnormalities in animal models ${ }^{83,84}$, and multiplication of the gene encoding $\alpha$-syn causes autosomal dominant disease in humans ${ }^{85}$. Two extensively studied missense mutations in the $\alpha$-syn gene, A53T and A30P, also cause autosomal dominant early onset Parkinson's ${ }^{86,87}$. For these reasons, much effort has been expended in the search for long-term therapies that enhance the clearance of intraneuronal $\alpha$-syn. Experimental evidence points to roles for both the ubiquitin-proteasome system (UPS) ${ }^{88,89}$, and the ALP in the degradation of wild-type (WT) $\alpha$-syn ${ }^{4}$. Because WT $\alpha$-syn contains the chaperone-mediated autophagy (CMA)-targeting motif, CMA is a major contributor to autophagic degradation of $\alpha$-syn ${ }^{90}$. However, in cases of intracellular $\alpha$-syn accumulation, where CMA is often disrupted ${ }^{91}$, macroautophagy is thought to take on a more significant compensatory role ${ }^{92}$, and so has been implicated in the clearance of toxic intracytoplasmic 
WT $\alpha$-syn oligomers ${ }^{92,93}$, A53T mutant $\alpha$-syn (which has a higher propensity to aggregate) $)^{94}$, and post-translationally modified $\alpha$-syn ${ }^{95}$.

\section{Defective autophagy in Parkinson's disease}

The overexpression or accumulation of $\alpha$-syn specifically disrupts the process of macroautophagy via a number of different mechanisms, blocking the degradation of autophagic substrates including $\alpha$-syn itself. Increased intracellular levels of pathogenic $\alpha$-syn can lead to Rab1a-mediated mislocalisation of the autophagy protein Atg9, inhibiting autophagosome biogenesis ${ }^{96}$. The D620N mutation in the vacuolar protein sorting-associated protein 35 (VPS35), which causes an autosomal dominant form of PD, is thought to result in a similar defect in ATG9 trafficking ${ }^{97}$, although this may not be the only factor contributing to the mutation's pathogenicity ${ }^{98}$. The observations that $\alpha$-syn accumulates in autophagosomes but not lysosomes in post-mortem PD brains ${ }^{99}$, and that the presence of $\alpha$-syn aggregates inhibits autophagosome maturation and fusion with lysosomes in vivo ${ }^{100}$, suggest that autophagic flux may also highly compromised by $\alpha$-syn accumulation. Lysosomal function may be impaired by mutant $\alpha$-syn, $\alpha$-syn oligomers, or post-translationally modified $\alpha$-syn, which are all poorly translocated into the lysosomal lumen ${ }^{94}$. Deficient autophagy is particularly disadvantageous for neuronal cells due to their post-mitotic nature, and can result in cell death due to oxidative stress ${ }^{101}$, or from the lack of clearance of damaged organelles, such as mitochondria ${ }^{102}$.

Other genes associated with PD risk have also been linked to autophagy. Mutations in the acid $\beta$-glucocerebrosidase (GBA1) gene are a strong genetic risk factor for $\mathrm{PD}^{103}$. iPSCderived neurons from PD patients with mutations in GBA1 show autophagic and lysosomal defects, including an accumulation of lysosomes, impairment of lysosomal hydrolytic function, and impaired fusion between autophagosomes and lysosomes ${ }^{81}$. Additionally, the PDassociated genes ATP13A2 and SYT11 regulate autophagy through a pathway mediated by 
TFEB ${ }^{104}$. Depletion of ATP13A2 appears to decrease levels of SYT11 via both transcriptional and post-translational mechanisms, and disruption of the pathway blocks autophagy ${ }^{104}$.

\section{Autophagy inducers in Parkinson's disease}

Rapamycin - an allosteric mTORC1 inhibitor ${ }^{105}$ - is one of the most frequently studied macroautophagy inducers, and has been shown to increase the clearance of WT, A30P, and A53T $\alpha$-syn in PC12 cells ${ }^{4}$, and to attenuate neuronal toxicity in dopaminergic neurons ${ }^{106}$. Beneficial effects have also been observed in vivo; rapamycin reduced $\alpha$-syn accumulation in transgenic $\alpha$-syn mice ${ }^{107}$, protected against MPTP-induced neuronal death in WT-mice ${ }^{108}$, and improved motor function in A53T transgenic mice ${ }^{109}$. In addition to stimulating autophagosome biogenesis $^{105}$, it has been proposed that rapamycin may increase lysosomal biogenesis ${ }^{106}$, thus potentially avoiding autophagosome accumulation and neuronal toxicity. It is noted that ATP-competitive mTOR inhibitors such as Torin-1 may be less suited for therapeutic purposes as they target both mTORC1 and mTORC2, as well as PI3K in some cases, and so induce neuronal toxicity on chronic administration ${ }^{110,111 .}$

A number of mTOR-independent autophagy inducers have also shown beneficial effects in PD models. Three novel small-molecule enhancers of rapamycin (SMERs) - SMER10, SMER18, and SMER28 - were identified by a chemical screen, and were shown to induce autophagic clearance of A53T $\alpha$-syn in vitro in an mTOR-independent manner ${ }^{112}$. The exact mechanisms by which each SMER exerts their effects on $\alpha$-syn have yet to be determined ${ }^{113}$.

The AMPK modulator trehalose enhances the clearance of A53T and A30P $\alpha$-syn in doxycycline-inducible PC12 cell lines, but not the clearance of WT $\alpha$-syn, which in these models was likely not strongly dependent on macroautophagy for its clearance ${ }^{45}$. In vivo studies have demonstrated similar autophagy-dependent results; oral administration of trehalose protects against tyrosine hydroxylase and dopamine transporter loss and reduces neuroinflammation in an MPTP induced PD mouse model ${ }^{114}$, and additionally prevents deficits in motor asymmetry in an adeno-associated virus (AAV)-mediated $\alpha$-syn overexpression rat 
model ${ }^{115}$. Trehalose treatment also decreases Akt activity, thereby activating the transcription factor TFEB and consequently the expression of autophagy and lysosomal genes ${ }^{116}$. A study which trialed the combined use of trehalose and the mTOR-dependant autophagy enhancer rapamycin in an MPTP-induced mouse model of PD further suggests that an additive effect may result from stimulating autophagy via different pathways ${ }^{117}$. Combined treatment in this case was more efficacious than either compound alone in reducing dopaminergic deficits and restoring expression of tyrosine hydroxylase, but did not improve cognition more than trehalose alone ${ }^{117}$.

A number of other AMPK-dependent autophagy inducers already in use for various clinical purposes have shown promise in cell and animal models of PD. Metformin (a drug currently used in the treatment of type 2 diabetes) induced a reduction in the levels of Ser-129 phosphorylated $\alpha$-syn in $\alpha$-syn overexpressing SH-SY5Y cells ${ }^{118}$, partially rescued mitochondrial dysfunction in genetic Drosophila models of $\mathrm{PD}^{119}$, and appeared neuroprotective in MPTP mice ${ }^{120}$. Nilotinib, a tyrosine-kinase inhibitor approved for use treating chronic myelogenous leukaemia, stimulated autophagy and partially rescued disease phenotype in both A53T and lentiviral $\alpha$-syn overexpression PD mouse models via inhibition of phosphorylation of $B C R-A B L^{121-123}$. A Phase 1 human clinical trial of nilotinib in PD patients with cognitive impairment showed improvements in cognitive and motor skills at doses of 150 $\mathrm{mg}$ and $300 \mathrm{mg}^{124}$. Phase 2 trials are currently ongoing and have so far generated promising results $^{124}$. The natural plant phenol resveratrol was shown to induce AMPK-dependent autophagy and $\alpha$-syn clearance in SH-SY5Y and PC12 cells, possibly via interaction with SIRT1 ${ }^{125,126}$. It also reduced the incidence of apoptosis in SH-SY5Y neuroblastoma cells exposed to rotenone ${ }^{127}$, protected against reactive oxygen species (ROS) in 6hydroxydopamine (6-OHDA)-induced rat PD models ${ }^{128,129}$, and appeared to be antineuroinflammatory in an MPTP mouse PD model ${ }^{130}$.

Corynoxine $\mathrm{B}$, an oxindole alkaloid isolated from a herb used in traditional Chinese medicine, has been shown to induce autophagy in multiple neuronal cell lines as well as in primary 
cortical neurons ${ }^{131}$. This led to enhanced clearance of WT, A53T, and A30P $\alpha$-syn monomers in differentiated dopaminergic neurons, and of $\alpha$-syn oligomers and $\alpha$-syn/synphillin-1 aggrosomes in N2a cells. The mechanism of autophagy induction was found to be mTORindependent, but appears to be mediated by Beclin- ${ }^{131}$. In cells subject to accumulation or overexpression of $\alpha$-syn, cytosolic translocation of HMGB1 is blocked, inhibiting the reaction between Beclin-1 and HMGB1 and thereby suppressing autophagy ${ }^{132}$. There is some data to suggest that corynoxine B can, under these same conditions, rescue the cytosolic localisation of HMGB1, thus rescuing the autophagy defect ${ }^{133}$. Corynoxine, an enantiomer of corynoxine B, was also shown to induce autophagy in SH-SY5Y and PC12 cell lines and to enhance the clearance of WT and A35T $\alpha$-synuclein, but interestingly via a different, Akt/mTOR dependent mechanism $^{134}$.

The mTOR-independent autophagic inducer lithium enhanced the clearance of A53T and A30P mutant $\alpha$-syn in inducible PC12 cell models ${ }^{59}$, protected $\mathrm{SH}-\mathrm{SY} 5 \mathrm{Y}$ neuroblastoma cells from rotenone induced toxicity ${ }^{135}$, and appeared to reduce Parkinsonian phenotypes in an aged Parkin mutant transgenic mouse model ${ }^{136}$. In addition to the aforementioned IP3dependent mechanism of autophagic induction, lithium may also act via inhibition of the GSK3 $\beta$ pathway. Activation of GSK3 $\beta$, an autophagy inhibitor, has been observed in $\alpha$-syn overexpression and MPTP models of PD, as well as in postmortem striatum of PD patients, and appears to be dependent on the presence of $\alpha-$ syn $^{137}$. Inhibition of GSK3 $\beta$ activity by lithium increases TFEB levels, and likely contributes to the compound's autophagy enhancing effects $^{137}$. Other mood-stabilising drugs have also been studied as potential autophagy inducers, and two - sodium valproate and carbamazepine - have been shown to induce autophagy and mimic the neuroprotective properties of lithium in SH-SY5Y cells exposed to rotenone $^{138}$ through an inositol-dependent mechanism. It has been reported that, as in the case of trehalose/rapamycin combination therapy, concomitant treatment of PC12 cells with lithium and rapamycin had an additive effect on the clearance of A53T $\alpha$-syn ${ }^{139}$, while combining lithium with sodium valproate partially ameliorated motor symptoms in an MPTP 
mouse PD model ${ }^{140}$. It is necessary to note that most known mood stabilising drugs affect multiple cellular processes, and as such may not be ideal therapeutic candidates.

\section{Genetic approaches in Parkinson's disease}

There is evidence to suggest that $\alpha$-syn accumulation may sequester the transcription factor TFEB in the cytoplasm, preventing its translocation into the nucleus and blocking its transcriptional activity ${ }^{141}$. This hypothesis is supported by the observations that nuclear TFEB levels were significantly reduced in the post-mortem PD midbrains, and that TFEB co-localised with filamentous $\alpha$-syn inclusions in neurons containing Lewy bodies ${ }^{142}$. While the extent to which TFEB is implicated in the pathogenesis of PD is still unclear, overexpression of TFEB has been shown to protect dopaminergic neurons from toxicity induced by AAV vectormediated overexpression of human $\alpha$-syn in the rat midbrain, and to protect against behavioural abnormalities in the same transgenic rat model ${ }^{142}$. Lentiviral overexpression of Beclin-1 also reduces $\alpha$-syn aggregation and ameliorates disease symptoms in a transgenic PD mouse model ${ }^{143}$.

Upregulation of autophagy represents an attractive therapeutic strategy in the treatment of PD, with phenotypic improvements observed in a number of in vivo and in vitro disease models. However, mutant, post-translationally modified, and oligomerised $\alpha$-syn negatively impact multiple distinct stages of the autophagic pathway, including lysosomal function. Therapies designed to stimulate autophagic flux, such as those targeting TFEB or combination therapies, may restore intraneuronal homeostasis without causing the accumulation of defective ALP components, and thus are likely to be of the greatest utility in the treatment of PD. 


\section{Polyglutamine diseases}

There are currently nine known diseases caused by polyglutamine expansion mutations: Huntington's disease (HD); spinal and bulbar muscular atrophy (SBMA); dentatorubropallidoluysian atrophy (DRPLA); and spinocerebellar ataxia (SCA) types 1, 2, 3, 6,7 , and $17^{144}$. These mutations are encoded by the expansion of a $(C A G)_{n}$ trinucleotide repeat tract in the relevant proteins. For example, in HD up to 35 CAGs are well-tolerated and considered within the range of normal variation, while 36 or more repeats cause disease. The mutant proteins cause disease via toxic gain-of-function mechanisms.

\section{Defective autophagy in polyglutamine diseases}

As aggregate-prone proteins containing polyQ expansions are substrates of autophagy, disruptions in the autophagy pathway may contribute to an accumulation of the relevant proteins and consequent toxicity. Additionally, recent studies have revealed that some of the genes associated with polyQ disease are themselves important regulators of autophagy in their wild-type forms. This suggests that disease pathology may be in part due to a direct inhibition of autophagy, rather than simply overwhelming the natural autophagic machinery with misfolded proteins ${ }^{8}$.

Wild-type HTT itself appears to play a complex and incompletely understood role in the autophagy pathway, and polyQ-expanded mutant huntingtin (mHTT) has been reported to impact autophagy in different ways. $\mathrm{mHTT}$ appears to impede cargo recognition ${ }^{145}$ by autophagosomes, which will slow substrate degradation. Interestingly, recent studies have proposed that wild-type HTT may act as a scaffold for selective autophagy ${ }^{146,147}$. This raises the possibility that disruption of the native function of wild-type HTT by mHTT may contribute to disruption of cargo recognition in $\mathrm{HD}$, although the precise mechanisms remain to be elucidated. Interestingly, expression of full-length HTT lacking its polyglutamine stretch $(\Delta \mathrm{Q}-$ htt) in vitro appears to increase autophagosome biogenesis and Atg5-dependent clearance of 
truncated $\mathrm{N}$-terminal mHTT aggregates ${ }^{148}$. As overexpression of full-length wild-type HTT in vitro does not increase autophagosome synthesis, this may represent a gain-of-function effect.

Additionally, polyQ-expanded proteins may cause defects in neuronal vesicular trafficking ${ }^{149}$. In neurons, autophagosomes are constitutively formed in the axon terminal and are trafficked by the microtubule motor-protein dynein towards the cell body after maturation ${ }^{150}$. Dynein mutations are linked to decreased clearance and increased toxicity of mutant HTT in flies and mice ${ }^{151}$, and polyQ proteins inhibit both anterograde and retrograde fast axonal transport in isolated axoplasm without the presence of aggregates ${ }^{152}$. Since this occurs without transcription or translation, this defect is likely due to direct protein-protein interactions. Interestingly, silencing of either wild-type HTT or its interactor, HTT-associated protein 1 (HAP1), was found to block retrograde transport of autophagosomes along axons ${ }^{153}$. The effect of HTT on retrograde transport appeared to be dependent on an interaction between HTT and dynein ${ }^{153,154}$. It is thus possible that polyQ-expanded HTT also disrupts autophagy by interfering with the function of wild-type protein. By impairing autophagosome and lysosome trafficking, polyQ-expanded proteins may inhibit their own degradation, leading to a positive feedback loop.

PolyQ-expanded proteins may also interfere with elements of the autophagy machinery. Wildtype Ataxin-3 has been shown to deubiquitinate Beclin-1, a critical component of autophagosome nucleation and maturation ${ }^{155}$, thereby protecting it from proteasomal degradation ${ }^{7}$. Interestingly, the polyQ tract in Ataxin-3 is the structural motif facilitating this interaction, representing a novel binding mechanism ${ }^{7}$. In fibroblasts derived from patients with $H D$, SCA3, or DRPLA, the longer polyQ tracts in the disease protein outcompete wild-type Ataxin-3 for this binding site, resulting in increased Beclin-1 degradation and consequently impaired starvation-induced autophagy ${ }^{7}$.

Some polyQ disease proteins may also disrupt the expression of autophagy and lysosomal genes through TFEB. Wild-type androgen receptor (AR) has been shown to coactivate TFEB, 
as evidenced by nuclear translocation of both following the addition of an androgen ligand to cell culture media, but this coactivation is lost in the polyQ-expanded AR that causes SBMA ${ }^{156}$. When in the nucleus, TFEB stimulates the CLEAR network of genes which increases lysosomal biogenesis ${ }^{157}$, and SBMA neurons exhibit a build-up of autophagosomes consistent with a block in degradation. This can be rescued by overexpression of TFEB, suggesting alternative activation of TFEB as a clinical strategy. DRPLA is caused by a polyglutamine expansion in atrophin-1 (ATN1). PolyQ-expanded ATN1 mice were found to exhibit reduced autophagic flux characterized by a block in degradation and inactivation of TFEB ${ }^{158}$. Furthermore, late-stage DRPLA appears to have impaired autophagosome degradation in flies $^{159}$.

\section{Autophagy inducers in polyglutamine diseases}

The presence of dense inclusion bodies containing the relevant polyQ-expanded proteins in post-mortem HD tissue initially led to the theory that protein aggregation was the prime driver of cytotoxicity. This theory was supported by in vitro studies which noted that long polyglutamine tracts destabilize peptide structure and cause proteins to be prone to aggregation ${ }^{160}$. Regardless of which species of protein is the most toxic, reducing the total pool of mutant protein ameliorates disease in cells, and autophagy upregulation has the potential to reduce the levels of both oligomers and aggregates. Since polyQ-expanded proteins are preferentially degraded by autophagy in cell models ${ }^{161}$ and inducing autophagy with rapamycin or other small molecules reduces the toxicity of polyQ-expanded huntingtin fragments in cells, flies, and mice ${ }^{3,67,112,139}$, it has thus been a longstanding idea that inducing autophagy prior to pathogenesis would be a viable strategy for postponing or preventing disease onset. The clearance of polyQ-expanded proteins by autophagy is particularly critical as polyQ aggregates may impair clearance by the proteasome ${ }^{162}$.

Autophagy enhancers from many different classes have been shown to be beneficial in cells and in vivo models of HD. Inducing autophagy with rapamycin reduces the toxicity of $\mathrm{mHTT}$ 
fragments in cells and mice ${ }^{3}$. Trehalose, a mTOR-independent autophagy inducer, has been found to increase motor function and lifespan in transgenic mice expressing $\mathrm{mHTT}^{163}$. The mTOR-independent small molecules SMER10, SMER18, and SMER28 similarly reduce mHTT toxicity in cells and Drosophila ${ }^{112}$. Combination therapy using rapamycin and lithium appears to provide greater protection against neurodegeneration in fly models, and thus combining mTOR-dependent and mTOR-independent enhancers may be a therapeutic option to explore ${ }^{164}$.

Additionally, the mTOR-independent small molecules loperamide, nimodipine, minoxidil, and rilmenidine were all found to ameliorate $\mathrm{mHTT}$ aggregation and toxicity in an autophagydependent manner in cells, as well as verapamil, clonidine, and calpastatin in both cells and zebrafish models ${ }^{67,165}$. Specifically, verapamil is an antagonist of the L-type $\mathrm{Ca}^{2+}$ channel, loperamide is an opioid receptor agonist, minoxidil opens the $\mathrm{K}^{+} \mathrm{ATP}$ channel, rilmenidine and clonidine are inhibitors of the imidazoline receptor, and calpastatin is a calpain inhibitor. Despite affecting such diverse targets, each of these drugs influence a common pathway which, when activated, increases cytoplasmic $\mathrm{Ca}^{2+}$ and cAMP levels and inhibits autophagy ${ }^{139}$. The search for novel autophagy inducers has yielded other interesting modulators. Nitric oxide (NO), a key signalling molecule, has been found to inhibit autophagosome synthesis via multiple pathways. These include inhibition of JNK1, which reduces phosphorylation of Bcl-2 and thereby enhances its inhibitory interaction with Beclin-1. NO also inhibits IKK $\beta$, which leads to a reduction in AMPK phosphorylation and activity. Depletion of NO via inhibitors of nitric oxide synthase increases autophagic flux and consequently ameliorates pathology in HD models ${ }^{166}$. Another study aiming to identify potent neuronal inducers of autophagy yielded a $\mathrm{N}^{10}$-substituted phenoxazine that, at proper doses, potently and safely up-regulated autophagy in neurons in an Akt- and mTOR-independent fashion ${ }^{167}$. Modulation of autophagy using CTEP, a negative allosteric modulator of metabotropic glutamate receptor 5 (mGluR5), was also reported to reduce HD pathology in Q175 huntingtin knock-in mice ${ }^{168}$. This effect 
appeared to be mediated through an autophagy pathway mediated by GSK3 $\beta$, ZBTB16, and ATG14.

For SBMA, anti-androgen treatment has also been a longstanding strategy ever since castrated mice were found to have reduced symptoms and improved lifespan ${ }^{169}$, and transgenic flies were found to only exhibit neurodegeneration upon treatment with androgen ligand, which was lost when the AR was trapped in the cytosol ${ }^{170}$. These findings suggest that nuclear translocation is a critical step in the pathogenesis of SBMA. Nuclear polyglutamine aggregates may not be as accessible to autophagy, which may contribute to their toxicity ${ }^{171}$. Further, treatment with direct AR antagonists such as enzalutamide and flutamide reduces toxicity in SBMA mice, co-treatment with autophagy inducers further decreases toxicity, and inhibiting autophagy increases toxicity ${ }^{172-174}$.

\section{Genetic approaches in polyglutamine diseases}

Several genetic interventions targeting autophagy have also been shown to have beneficial effects in cell and animal models of HD. Overexpression of constitutively active AMPK- $\alpha$ as well as treatment with the AMPK activator A769662 induces autophagy, reduced aggregation, and improved cell viability in STHdh cells and mouse embryonic fibroblasts ${ }^{175}$. Overexpression of Rab5, which complexes with Vps34 and Beclin-1 was also found to enhance autophagosome formation and attenuate toxicity in cell and Drosophila models of $\mathrm{HD}^{176}$. Genetic ablation of XBP1 also appears to increase $\mathrm{mHTT}$ clearance and ameliorate HD pathology in cell and mouse models of $\mathrm{HD}^{177}$. This effect appears to occur via a mechanism involving autophagy, as depletion of XBP1 increased levels of FOXO1 and consequently the transcription of autophagy-related genes. In a mouse model of $\mathrm{HD}$, restoration of $P G C-1 \alpha$ (which is inhibited by $\mathrm{mHTT}$ ) reduced $\mathrm{mHTT}$ aggregation and ameliorated disease symptoms via a pathway involving the activation of TFEB ${ }^{178}$. Finally, the deubiquitinase Usp12 was recently identified as another inducer of neuronal autophagy ${ }^{179}$. In neurons derived from HD 
patients and rodent models as well as in Drosophila, overexpression of Usp12 increased autophagic flux and rescued $\mathrm{mHTT}$ neurotoxicity in an autophagy-dependent manner ${ }^{179}$.

Interestingly, expression of full-length HTT lacking its polyglutamine stretch ( $\Delta \mathrm{Q}-\mathrm{htt})$ in a knockin mouse model for $\mathrm{HD}\left(H d h^{140 \mathrm{Q} / \Delta \mathrm{Q}}\right)$ significantly reduces levels of $\mathrm{mHTT}$ aggregates, ameliorates neurological defects, and extends lifespan in comparison to HD model mice $\left(H d h^{140 Q /+}\right)^{148}$. This was found together with an increase in steady-state levels of the autophagic marker LC3-II, suggesting that the beneficial effects may be due to an increase in autophagy. In support of this, overexpression of $\Delta Q$-htt in cells was shown to increase autophagic clearance. Furthermore, $\mathrm{Hdh}^{\Delta \mathrm{Q} / \Delta \mathrm{Q}}$ mice (expressing only $\Delta \mathrm{Q}$-htt without polyQexpanded htt) show a significant increase in lifespan in comparison with WT mice, suggesting that the increase in autophagy caused by $\Delta Q$-htt may also have effects on longevity in normal mice.

Induction of more specific forms of autophagy may also be of therapeutic benefit in HD. One element of HD pathology appears to be impaired clearance of defective mitochondria. ${ }^{180}$ Overexpression of PINK1, a critical mitophagy gene, alleviated mitochondrial pathology, ATP levels, neuronal integrity and adult fly survival in a genetic Drosophila model of $\mathrm{HD}^{180}$.

Genetic induction of autophagy has also been tested in other polyglutamine diseases. Spinocerebellar ataxia type 3 (SCA3), also known as Machado-Joseph disease, is an autosomal dominant disease caused by a polyQ expansion in the Ataxin-3 gene. In neuroblastoma and rat models of SCA3, lentiviral overexpression of Beclin-1 increased autophagic flux, increased the clearance of mutant Ataxin-3, and appeared to reduce neuronal pathology in the striatum of the rat model ${ }^{181}$. A subsequent study of lentiviral Beclin-1 overexpression in a transgenic SCA3 mouse model showed similar marked improvements in aggregate clearance and neuropathology, and additionally demonstrated significant improvements in motor coordination, balance and gait ${ }^{182}$. 
Together, these data suggest that polyQ diseases are amenable to activation of autophagy via a variety of pathways and using a variety of drugs. Because polyQ diseases may be diagnosed presymptomatically, a prospective therapeutic strategy may be to begin treatment before disease onset in order to postpone neuronal loss. 


\section{Amyotrophic lateral sclerosis}

Amyotrophic lateral sclerosis (ALS) is a fatal neurodegenerative disease which is characterized by progressive degeneration of upper and lower motor neurons. The majority ( $90 \%)$ of ALS cases are sporadic, and only $5-10 \%$ of all cases have been reported to be familial ${ }^{183}$. A large number of pathogenic mutations within over 30 genes have been linked to ALS. The most commonly involved genes are superoxide dismutase $(S O D 1)^{184}$, fused in sarcoma $(F U S)^{185}$, TAR DNA-binding protein 43 (TDP-43) $)^{186}$, sequestosome 1 $(S Q S T M 1 / p 62)^{187,}{ }^{188}$, optineurin $(O P T M)^{189}$, valosin-containing protein $(V C P)^{190}$, TANK binding kinase $1(T B K 1)^{191}$, ubiquilin $2(U B Q L N 2)^{192}$, dynactin subunit $1(\text { (DCTN1) })^{193}$, alsin $(A L S 2)^{194}$, profilin $1(P F N 1)^{195}$, charged multivesicular body protein 2B $(C H M P 2 B)^{196,197}$, factor-induced gene 4 (FIG4) ${ }^{198}$, and a hexanuleotide repeat expansion (GGGGCC) found in the C9orf72 gene ${ }^{199}$. Mutations in these genes affect multiple cellular pathways including protein quality control, axonal transport and RNA metabolism ${ }^{200}$. The abundance of ubiquitinpositive inclusions is a characteristic neuropathological feature in ALS, indicating impairment of protein quality control systems. Interestingly, these inclusions were also found to be positive for mutant SOD1 and TDP-43 in transgenic mice and patients ${ }^{201-203}$.

\section{Defective autophagy in ALS}

Since many genes linked to ALS impact autophagy, it is believed that dysfunctional autophagy is one of the critical elements in the disease. Several of these genes encode various autophagy receptors, which are vital for the recruitment of specific cargo to autophagosomes for degradation ${ }^{204}$. These receptors share common domains such as a ubiquitin-associated domain (UBA) and a LC3-interacting region (LIR); the former enables binding to ubiquitinated

substrates while the latter facilitates loading onto the developing phagophore ${ }^{205}$. Mutations in a number of autophagy receptors, including SQSTM1/p62, OPTN and UBQLN2, have been associated with the pathogenesis of ALS, as described below. 
SQSTM1/p62 is found in ubiquitin-positive inclusions of mutant SOD1 (mSOD1) in motor neurons of ALS mouse models. Mutations in p62 are implicated in ALS, including an ALSlinked L341V substitution mapped to the p62 LIR, which abrogates its interaction with LC3B and hence interferes with the loading of p62 onto the phagophore 206 .

A number of mutations in OPTN are associated with both familial and sporadic cases of ALS ${ }^{189}$, 207. These mutations include a homozygous deletion of exon 5, a homozygous Q398X nonsense mutation, and a heterozygous E478G missense mutation. The E478G mutation in the UBA of OPTN abolishes its interaction with ubiquitin but does not affect its capacity to interact with mutant SOD1 via its C-terminal coiled-coil domain. Also, downregulation of OPTN in a mutant SOD1 G93A zebrafish ALS model using morpholinos exacerbates motor axonopathy ${ }^{189,208}$. Additional mutations in the UBA domain of OPTN, Q398X and E478G, impede autophagosome maturation, since these mutant forms cannot recruit MYO6, which facilitates fusion of autophagosomes to endosomes and ultimately degradation of autophagosomes $^{209,210 .}$.

Ubiquilin 2 (UBQLN2) aids in the appropriate identification of ubiquitinated misfolded proteins by p62 through its UBA domain. Overexpression of the ALS-linked mutant P497H UBQLN2 imparts a toxic gain of function in a rat model and causes defects in autophagy by disrupting endosomal pathways ${ }^{211}$.

The ALS-associated gene ALS2, which encodes alsin, has also been found to impact autophagy. Alsin is a guanine nucleotide exchange factor for Rab5 and this interaction is mediated by the Vps9p domain of alsin. Genetic ablation of ALS2 in SOD1 ${ }^{\mathrm{H} 46 \mathrm{R}}$ mice exacerbated the disease phenotype by disturbing the cascade of autophagosome maturation and lysosomal fusion, as alsin has been shown to associate with p62 and LC3 to facilitate autophagic clearance by maintaining balanced endosomal fusion ${ }^{212,213}$. Moreover, simultaneous depletion of $\mathrm{p} 62$ and ALS2 in a mutant SOD1 ${ }^{\mathrm{H} 46 \mathrm{R}}$ mouse model aggravated disease, providing further evidence that both of these independent ALS-linked genes protect against the disease through the autophagy-endolysosomal axis ${ }^{214}$. 
Common disease models of ALS show complex alterations to autophagy that remain incompletely understood. One widely used model is mutations in the SOD1 gene, which encodes a $\mathrm{Cu}-\mathrm{Zn}$ superoxide dismutase that converts reactive superoxide radicals to hydrogen peroxide and oxygen in order to relieve oxidative stress in cells. Mutations in SOD1 constitute almost $20 \%$ of familial cases of ALS, and are among the most widely studied genetic causes of the disease ${ }^{184}$. Early evidence indicated that transgenic SOD1 ${ }^{\mathrm{G} 93 \mathrm{~A}}$ mouse model of ALS shows increased numbers of autophagosomes, compared with non-transgenic or human wild-type SOD1 transgenic animals ${ }^{215}$. As later studies have also found endolysosomal deficits and reduced substrate clearance in SOD1 ${ }^{\mathrm{G} 93 \mathrm{~A}}$ mice, this increased number may be due to a block in autophagosomal degradation ${ }^{216}$. TDP-43 has also been found to positively regulate autophagy by stabilizing ATG7 mRNA in cells, and depletion of TDP-43 results in autophagy impairment and accumulation of aggregate-prone proteins ${ }^{217}$. Disruption to native TDP-43 function in disease states (e.g. by sequestration in aggregates) may thus impair autophagy.

A hexanucleotide $\left(\mathrm{G}_{4} \mathrm{C}_{2}\right)$ repeat expansion in C9orf72 accounts for $25 \%$ of familial cases and $10 \%$ of sporadic cases ${ }^{199}$ of ALS. Its contribution to ALS pathogenesis is multitudinous as the mutated RNA form can affect transcription of wild-type C9orf72, can accumulate in RNA foci inside the nucleus and can sequester RNA binding proteins such as TDP-43 and FUS. The translated products of $\mathrm{G}_{4} \mathrm{C}_{2}$ C9orf72 are toxic dipeptides which disrupt nucleocytoplasmic transport ${ }^{218}$, aggregate with $\mathrm{p} 62^{219}$, and inhibit the proteasome ${ }^{220}$. Loss of C9orf72 inhibits initiation of ULK1-mediated autophagy by disrupting the SMCR8-C9orf72 complex. On the contrary, depletion of C9orf72 can induce TFEB-mediated autophagy by inhibiting $\operatorname{mTORC} 1^{221,222 .}$

\section{Autophagy inducers in ALS}

Autophagy induction has shown beneficial effects in cells harbouring pathogenic SOD1 mutations. In Neuro2a cells, G93A mutant SOD1 is a substrate for autophagy mediated degradation, as pharmacological inhibition of autophagy led to its accumulation whereas augmenting autophagy with rapamycin resulted in reduced protein levels ${ }^{223}$. Recently, a study 
has reported that p-coumaric acid (active ingredient present in Brazilian green propolis) exerted protective effects against neurotoxicity caused by pathogenic SOD1 ${ }^{\mathrm{G} 85 \mathrm{R}}$ in Neuro2a cells via activation of autophagy ${ }^{224}$.

Although advantageous effects of enhancing autophagy have been shown for these in vitro models, the evidence for in vivo SOD1 models of ALS has been mixed. One study reported unexpectedly detrimental effects upon rapamycin treatment in a SOD1 ${ }^{\mathrm{G} 93 \mathrm{~A}}$ mouse model, where rapamycin treated mice exhibited earlier onset of disease, shorter lifespan, and greater weight loss ${ }^{225}$. Although the autophagic activity was increased in the motor neurons of these mice upon rapamycin treatment, there was no apparent reduction in SOD1 aggregation. The observed accelerated disease progression was attributed to activation of the apoptotic pathway in spinal cords of ALS mice treated with rapamycin, as confirmed by increased levels of cleaved caspase- $3^{225}$. In contrast, another study in a SOD1 ${ }^{\mathrm{G} 93 \mathrm{~A}}$ mouse model using verapamil (L-type channel $\mathrm{Ca}^{2+}$ blocker) showed beneficial effects. Verapamil, an enhancer of autophagy, effectively delayed disease onset, prolonged life span, extended disease duration, rescued motor neuron survival, reduced SOD1 aggregation, and restored autophagic flux in motor neurons ${ }^{226}$. Furthermore, at least two studies have found beneficial effects of trehalose in alleviating ALS disease pathology. In mutant $\mathrm{SOD} 1^{\mathrm{G} 86 \mathrm{R}}$ and $\mathrm{SOD} 1^{\mathrm{G} 93 \mathrm{~A}}$ transgenic mice, trehalose administration resulted in increased life span, improved neuronal survival, reduced astrogliosis and delayed disease onset through activation of autophagy. However, it was beneficial only in early stages of the disease and was recommended for use in combination with other ALS drugs for asymptomatic patients ${ }^{227,228}$.

Other commonly used models of ALS pathology utilise FUS and TDP-43. These are aggregrate-prone RNA binding proteins, which are known to cause altered RNA metabolism in ALS. Similarly to SOD1, the pathogenic form of TDP-43 is degraded by autophagy 229,230 . Mutant FUS (mFUS) inhibits autophagy by reducing ATG9 recruitment to autophagosomes and concomitantly decreasing autolysosome formation. A study using iPSC-derived neurons recapitulating FUS-related ALS disease pathology showed that mTOR inhibitors, such as 
torkinib and PQR309, expedited the clearance of cytoplasmic FUS and restored altered RNA metabolism via autophagy induction ${ }^{231}$.

Results from autophagy induction in TDP-43 models have been mixed. Rapamycin was shown to be beneficial in a FTLD-TDP transgenic mouse model of $A L S^{232}$. Autophagy upregulation using the novel compounds fluphenazine, methotrimeprazine and $10-\left(4^{\prime}-(\mathrm{N}-\right.$ diethylamino)butyl)-2-chlorophenoxazine in a neuronal model of ALS also reduced TDP-43 levels and ameliorated pathology ${ }^{233}$. However, enhancement of autophagosome biogenesis by rapamycin in a Drosophila model of TDP-43 pathology aggravated the disease, whereas impeding autophagy by phosphatidic acid (an mTOR agonist ${ }^{234}$ ) ameliorated the disease phenotype $e^{235}$.

The complex results obtained from autophagy upregulation in TDP-43 models may be explained by the specific defects in autophagy present in the disease. Loss-of TDP-43 function may occur in disease conditions when the normally nuclear protein is unable to localise correctly. This may have multiple effects on autophagy. TDP-43 stabilizes the mRNA levels of RPTOR (a component of mTORC1), and loss of function of TDP-43 results in downregulation of RPTOR which affects mTORC1 activity ${ }^{235}$. TFEB, a positive regulator of autophagosome and lysosome biogenesis is phosphorylated by mTORC1, which inhibits its translocation to the nucleus. Loss of function of TDP-43 thus causes induction of autophagy by reducing mTORC1 activity, consequently enhancing TFEB nuclear translocation. However, this autophagy induction is not beneficial as loss of TDP-43 also results in decreased dynactin-1 levels, which impairs autophagosome-lysosome fusion ${ }^{235}$. This downstream block in autophagic flux may cause a deleterious accumulation of autophagosomes if autophagosome formation is induced.

\section{Genetic approaches in ALS}

In addition to pharmacological studies, several genetic manipulations have been shown to alter ALS pathology through autophagy. The effect of these manipulations appears to vary 
substantially for each gene and disease model. For example, genetic ablation of $X B P-1$ (Xbox-binding protein) in motor neurons of SOD1 ${ }^{\mathrm{G} 86 \mathrm{R}}$ mice enhanced clearance of mutant SOD1 aggregates and increased survival through autophagy ${ }^{236}$. In contrast, conditional knockout of ATG7 in motor neurons of SOD1G93A mice led to extended lifespan and reduced cellnonautonomous effects on glial cells in the early stages of disease yet accelerated disease pathology 237 .

Overexpression of Beclin-1 has also yielded complex effects on ALS pathology. BECN1 overexpression in NSC34 motor neuron cells decreased the aggregation of mutant SOD1 ${ }^{\text {G85R }}$ protein $^{238}$. In a SOD1 ${ }^{\mathrm{G} 127 \mathrm{X}}$ mouse model, heterozygous loss of Beclin-1 reduced autophagic flux and led to increased SOD1 ${ }^{\mathrm{G} 127 \mathrm{X}}$ aggregation ${ }^{239}$. However, haploinsufficiency of BECN1 in mutant SOD1 ${ }^{\mathrm{G} 86 \mathrm{R}}$ transgenic mice was associated with increased life span and reduction in mutant SOD1 oligomers, accompanied by an increase in monomeric and high molecular weight species impacting aggregation, without an apparent change in mRNA levels ${ }^{238}$. In this case, the reduction in oligomeric species was suggested to be protective. The contrasting results between these two studies suggest that different ALS mutations or risk factors may interact in different ways with the autophagy pathway.

Positive results have been obtained in a mFUS model of the disease ${ }^{240}$. Overexpression of Rab1, which mediates intracellular membrane trafficking events, including ER-Golgi trafficking and autophagosome formation, rescued autophagosome and autolysosome formation in cells expressing mFUS. Moreover, Rab1 overexpression inhibited recruitment of mFUS to stress granules (SGs), resulting in a reduction in their size ${ }^{240}$.

As ALS is caused by mutations in many different genes which may impact autophagy differently, it may be necessary to consider the specific effects of each individual mutation when considering autophagy-related therapies. This may be particularly relevant when these genes directly impact different parts of the autophagy itinerary. 


\section{Conclusion and perspective}

Deficits in protein homeostasis are a shared mechanism across neurodegenerative diseases, and therefore increasing protein clearance via autophagy is an attractive strategy that may be applicable in multiple diseases. As described above, evidence in disease models indeed demonstrates promising results in many cases, with autophagy upregulation being able to reduce the levels of toxic proteins, ameliorate signs of disease, and delay disease progression in a number of models.

Effectively utilising autophagy induction as a therapy, however, requires a thorough understanding of the interplay between disease pathogenesis and autophagy. Despite the strong positive results seen in some models, the complex and often apparently contradictory results obtained in other disease models indicate that the effects of autophagy upregulation may vary substantially depending on the precise nature of the disease state. The complex and varied impairments to autophagy seen in different diseases make it especially important to understand how autophagy impacts (and is impacted by) pathogenesis mediated by each mutant protein. For instance, as some disease-causing mutations may generate disruptions to lysosomal function as part of their pathogenesis, induction of autophagy in these cases may result in accumulation of autophagosomes that cannot be degraded, resulting in an amplification of the pathological phenotype. The pathophysiology of many neurodegenerative diseases is incompletely understood, particularly in sporadic cases of illness. A better understanding of how the autophagy pathway is affected in these cases can help researchers to design tailored and effective treatments. It is also important to consider effects autophagy may have on pathways unrelated to protein clearance, such as secretion, which may also affect disease.

Upstream signalling pathways such as mTORC1, TFEB and AMPK may exert influence across the whole pathway and thus are a potential target to improve flux and overall protein clearance. However, while some compounds acting on these pathways (e.g. rapamycin) are used therapeutically in humans, the many roles of pleiotropic targets such as mTOR and 
AMPK may lead to undesirable side effects resulting from their inhibition. As autophagy induction may be more beneficial in early stages of disease ${ }^{61,225,228}$, finding modulators with mild long-term side effect profiles would be of great therapeutic benefit. Identifying more specific autophagy regulators that are still able to improve flux may lead to drug targets that could be modulated in a more clinically tolerable manner. Pharmacokinetic optimisation of treatments may also help to reduce side effects from autophagy treatment, and there is some evidence that pulsatile treatment may suffice to effectively promote protein clearance ${ }^{3}$ while potentially limiting side effects. 


\section{Figure and table legends:}

Figure 1. Defective autophagy and neurodegenerative disease. A number of risk genes linked to neurodegenerative diseases play a role in the autophagy pathway. These genes intersect with the autophagy pathway at many different stages, as indicated here. Disruptions to autophagy caused by pathogenic changes to the relevant genes may contribute to disease pathogenesis.

Figure 2. Small molecule inducers of autophagy and their mechanisms of action. Autophagy is regulated by the mTORC1 pathway and inhibitors of $\mathrm{mTORC} 1$, including rapamycin and rapalogs, are among the best studied class of autophagy inducers. Other modulators are classed as mTOR-independent, and act on various targets including AMPK, IP 3 signalling, and $\mathrm{Ca}^{2+}$ signalling.

Table 1. Autophagy inducing molecules that have been tested in models of neurodegenerative disease and pilot clinical studies.

\section{Acknowledgements:}

We are grateful for funding from the UK Dementia Research Institute (funded by the MRC, Alzheimer's Research UK and the Alzheimer's Society), Roger de Spoelberch Foundation, Alzheimer's Research UK, The Tau Consortium, Cambridge Centre for Parkinson-Plus, National Institute for Health Research Cambridge Biomedical Research Centre (D.C.R.), Cambridge Commonwealth, European \& International Trust (to AD, SK, and RP); Romanian grant of Ministry of Research and Innovation CNCS -UEFISCDI, project number PN-III-P11.1-PD-2016-1291, within PNCDI III (to MP); the National Institutes of Health OxfordCambridge Scholars Program (to RP); Cambridge Australia Scholarships (to AD); the Nehru Trust for Cambridge University (to SK); the Trinity-Henry Barlow Scholarship (to SK); Udayan Care (to SK); the UK Medical Research Council (to LR); and the Raymond and Beverly Sackler Fund (to LR). The views expressed are those of the author(s) and not necessarily those of the NHS, the NIHR or the Department of Health and Social Care. 


\section{References:}

[1] Menzies FM, Fleming A, Caricasole A, Bento CF, Andrews SP, Ashkenazi A, et al. Autophagy and Neurodegeneration: Pathogenic Mechanisms and Therapeutic Opportunities. Neuron. 2017;93:101534.

[2] Bento CF, Renna M, Ghislat G, Puri C, Ashkenazi A, Vicinanza M, et al. Mammalian autophagy: how does it work? Annu Rev Biochem. 2016;85:685-713.

[3] Ravikumar B, Vacher C, Berger Z, Davies JE, Luo S, Oroz LG, et al. Inhibition of mTOR induces autophagy and reduces toxicity of polyglutamine expansions in fly and mouse models of Huntington disease. Nat Genet. 2004;36:585-95.

[4] Webb JL, Ravikumar B, Atkins J, Skepper JN, Rubinsztein DC. Alpha-Synuclein is degraded by both autophagy and the proteasome. J Biol Chem. 2003;278:25009-13.

[5] Schaeffer V, Lavenir I, Ozcelik S, Tolnay M, Winkler DT, Goedert M. Stimulation of autophagy reduces neurodegeneration in a mouse model of human tauopathy. Brain. 2012;135:2169-77.

[6] Winslow AR, Rubinsztein DC. The Parkinson disease protein alpha-synuclein inhibits autophagy. Autophagy. 2011;7:429-31.

[7] Ashkenazi A, Bento CF, Ricketts T, Vicinanza M, Siddiqi F, Pavel M, et al. Polyglutamine tracts regulate beclin 1-dependent autophagy. Nature. 2017;545:108-11.

[8] Menzies FM, Fleming A, Rubinsztein DC. Compromised autophagy and neurodegenerative diseases. Nat Rev Neurosci. 2015;16:345-57.

[9] Rubinsztein DC, Shpilka T, Elazar Z. Mechanisms of autophagosome biogenesis. Curr Biol. 2012;22:R29-34.

[10] Liang XH, Jackson S, Seaman M, Brown K, Kempkes B, Hibshoosh H, et al. Induction of autophagy and inhibition of tumorigenesis by beclin 1. Nature. 1999;402:672-6.

[11] Russell RC, Tian Y, Yuan H, Park HW, Chang YY, Kim J, et al. ULK1 induces autophagy by phosphorylating Beclin-1 and activating VPS34 lipid kinase. Nat Cell Biol. 2013;15:741-50.

[12] Fujita N, Hayashi-Nishino M, Fukumoto H, Omori H, Yamamoto A, Noda T, et al. An Atg4B mutant hampers the lipidation of LC3 paralogues and causes defects in autophagosome closure. Mol Biol Cell. 2008;19:4651-9.

[13] Kimura S, Noda T, Yoshimori T. Dynein-dependent movement of autophagosomes mediates efficient encounters with lysosomes. Cell Struct Funct. 2008;33:109-22.

[14] Hosokawa N, Hara T, Kaizuka T, Kishi C, Takamura A, Miura Y, et al. Nutrient-dependent mTORC1 association with the ULK1-Atg13-FIP200 complex required for autophagy. Mol Biol Cell. 2009;20:198191.

[15] Settembre C, Di Malta C, Polito VA, Garcia Arencibia M, Vetrini F, Erdin S, et al. TFEB links autophagy to lysosomal biogenesis. Science. 2011;332:1429-33.

[16] Brown RH, Al-Chalabi A. Amyotrophic lateral sclerosis. N Engl J Med. 2017;377:162-72.

[17] Jimenez-Sanchez M, Licitra F, Underwood BR, Rubinsztein DC. Huntington's Disease: Mechanisms of Pathogenesis and Therapeutic Strategies. Cold Spring Harb Perspect Med. 2017;7:a024240.

[18] Dehay B, Bourdenx M, Gorry P, Przedborski S, Vila M, Hunot S, et al. Targeting alpha-synuclein for treatment of Parkinson's disease: mechanistic and therapeutic considerations. Lancet Neurol. 2015;14:855-66.

[19] De Strooper B, Karran E. The Cellular Phase of Alzheimer's Disease. Cell. 2016;164:603-15.

[20] Lee VM, Goedert M, Trojanowski JQ. Neurodegenerative tauopathies. Annu Rev Neurosci. 2001;24:1121-59.

[21] Hansen M, Rubinsztein DC, Walker DW. Autophagy as a promoter of longevity: insights from model organisms. Nat Rev Mol Cell Biol. 2018;19:579-93.

[22] Pickford F, Masliah E, Britschgi M, Lucin K, Narasimhan R, Jaeger PA, et al. The autophagy-related protein beclin 1 shows reduced expression in early Alzheimer disease and regulates amyloid beta accumulation in mice. J Clin Invest. 2008;118:2190-9.

[23] Nixon RA. The role of autophagy in neurodegenerative disease. Nat Med. 2013;19:983-97. 
[24] Shibata M, Lu T, Furuya T, Degterev A, Mizushima N, Yoshimori T, et al. Regulation of intracellular accumulation of mutant Huntingtin by Beclin 1. J Biol Chem. 2006;281:14474-85.

[25] Rohn TT, Wirawan E, Brown RJ, Harris JR, Masliah E, Vandenabeele P. Depletion of Beclin-1 due to proteolytic cleavage by caspases in the Alzheimer's disease brain. Neurobiol Dis. 2011;43:68-78.

[26] Brehme M, Voisine C, Rolland T, Wachi S, Soper JH, Zhu Y, et al. A chaperome subnetwork safeguards proteostasis in aging and neurodegenerative disease. Cell Rep. 2014;9:1135-50.

[27] Pavel M, Imarisio S, Menzies FM, Jimenez-Sanchez M, Siddiqi FH, Wu X, et al. CCT complex restricts neuropathogenic protein aggregation via autophagy. Nat Commun. 2016;7:13821.

[28] Jun G, Naj AC, Beecham GW, Wang LS, Buros J, Gallins PJ, et al. Meta-analysis confirms CR1, CLU, and PICALM as alzheimer disease risk loci and reveals interactions with APOE genotypes. Arch Neurol. 2010;67:1473-84.

[29] Ando K, Brion JP, Stygelbout V, Suain V, Authelet M, Dedecker R, et al. Clathrin adaptor CALM/PICALM is associated with neurofibrillary tangles and is cleaved in Alzheimer's brains. Acta Neuropathol. 2013;125:861-78.

[30] Moreau K, Fleming A, Imarisio S, Lopez Ramirez A, Mercer JL, Jimenez-Sanchez M, et al. PICALM modulates autophagy activity and tau accumulation. Nat Commun. 2014;5:4998.

[31] Lee JH, Yu WH, Kumar A, Lee S, Mohan PS, Peterhoff CM, et al. Lysosomal proteolysis and autophagy require presenilin 1 and are disrupted by Alzheimer-related PS1 mutations. Cell. 2010;141:1146-58.

[32] Lee JK, Jin HK, Park MH, Kim BR, Lee PH, Nakauchi H, et al. Acid sphingomyelinase modulates the autophagic process by controlling lysosomal biogenesis in Alzheimer's disease. J Exp Med. 2014;211:1551-70.

[33] Ji ZS, Mullendorff K, Cheng IH, Miranda RD, Huang Y, Mahley RW. Reactivity of apolipoprotein E4 and amyloid beta peptide: lysosomal stability and neurodegeneration. J Biol Chem. 2006;281:268392.

[34] Cataldo AM, Peterhoff CM, Troncoso JC, Gomez-Isla T, Hyman BT, Nixon RA. Endocytic pathway abnormalities precede amyloid beta deposition in sporadic Alzheimer's disease and Down syndrome: differential effects of APOE genotype and presenilin mutations. Am J Pathol. 2000;157:277-86.

[35] Shi Y, Yamada K, Liddelow SA, Smith ST, Zhao L, Luo W, et al. ApoE4 markedly exacerbates taumediated neurodegeneration in a mouse model of tauopathy. Nature. 2017;549:523-7.

[36] Xu W, Weissmiller AM, White JA, 2nd, Fang F, Wang X, Wu Y, et al. Amyloid precursor proteinmediated endocytic pathway disruption induces axonal dysfunction and neurodegeneration. J Clin Invest. 2016;126:1815-33.

[37] Boland B, Kumar A, Lee S, Platt FM, Wegiel J, Yu WH, et al. Autophagy induction and autophagosome clearance in neurons: relationship to autophagic pathology in Alzheimer's disease. J Neurosci. 2008;28:6926-37.

[38] Nixon RA, Wegiel J, Kumar A, Yu WH, Peterhoff C, Cataldo A, et al. Extensive involvement of autophagy in Alzheimer disease: an immuno-electron microscopy study. J Neuropathol Exp Neurol. 2005;64:113-22.

[39] Ejlerskov P, Ashkenazi A, Rubinsztein DC. Genetic enhancement of macroautophagy in vertebrate models of neurodegenerative diseases. Neurobiol Dis. 2019;122:3-8.

[40] Lopez A, Lee SE, Wojta K, Ramos EM, Klein E, Chen J, et al. A152T tau allele causes neurodegeneration that can be ameliorated in a zebrafish model by autophagy induction. Brain. 2017;140:1128-46.

[41] Jiang T, Yu JT, Zhu XC, Zhang QQ, Cao L, Wang HF, et al. Temsirolimus attenuates tauopathy in vitro and in vivo by targeting tau hyperphosphorylation and autophagic clearance. Neuropharmacology. 2014;85:121-30.

[42] Ozcelik S, Fraser G, Castets P, Schaeffer V, Skachokova Z, Breu K, et al. Rapamycin attenuates the progression of tau pathology in P301S tau transgenic mice. PLoS One. 2013;8:e62459. 
[43] Spilman P, Podlutskaya N, Hart MJ, Debnath J, Gorostiza O, Bredesen D, et al. Inhibition of mTOR by rapamycin abolishes cognitive deficits and reduces amyloid-beta levels in a mouse model of Alzheimer's disease. PLoS One. 2010;5:e9979.

[44] Berger Z, Ravikumar B, Menzies FM, Oroz LG, Underwood BR, Pangalos MN, et al. Rapamycin alleviates toxicity of different aggregate-prone proteins. Hum Mol Genet. 2006;15:433-42.

[45] Sarkar S, Davies JE, Huang Z, Tunnacliffe A, Rubinsztein DC. Trehalose, a novel mTOR-independent autophagy enhancer, accelerates the clearance of mutant huntingtin and alpha-synuclein. J Biol Chem. 2007;282:5641-52.

[46] Renna M, Jimenez-Sanchez M, Sarkar S, Rubinsztein DC. Chemical inducers of autophagy that enhance the clearance of mutant proteins in neurodegenerative diseases. I Biol Chem. 2010;285:11061-7.

[47] DeBosch BJ, Heitmeier MR, Mayer AL, Higgins CB, Crowley JR, Kraft TE, et al. Trehalose inhibits solute carrier 2A (SLC2A) proteins to induce autophagy and prevent hepatic steatosis. Sci Signal. 2016;9:ra21.

[48] Rodriguez-Navarro JA, Rodriguez L, Casarejos MJ, Solano RM, Gomez A, Perucho J, et al. Trehalose ameliorates dopaminergic and tau pathology in parkin deleted/tau overexpressing mice through autophagy activation. Neurobiol Dis. 2010;39:423-38.

[49] Luengo E, Buendia I, Fernandez-Mendivil C, Trigo-Alonso P, Negredo P, Michalska P, et al. Pharmacological doses of melatonin impede cognitive decline in tau-related Alzheimer models, once tauopathy is initiated, by restoring the autophagic flux. J Pineal Res. 2019;67:e12578.

[50] Hashimoto Y, Niikura T, Tajima H, Yasukawa T, Sudo H, Ito $Y$, et al. A rescue factor abolishing neuronal cell death by a wide spectrum of familial Alzheimer's disease genes and Abeta. Proc Natl Acad Sci U S A. 2001;98:6336-41.

[51] Han K, Jia N, Zhong Y, Shang X. S14G-humanin alleviates insulin resistance and increases autophagy in neurons of APP/PS1 transgenic mouse. J Cell Biochem. 2018;119:3111-7.

[52] Ou Z, Kong X, Sun X, He X, Zhang L, Gong Z, et al. Metformin treatment prevents amyloid plaque deposition and memory impairment in APP/PS1 mice. Brain Behav Immun. 2018;69:351-63.

[53] Lonskaya I, Hebron ML, Selby ST, Turner RS, Moussa CE. Nilotinib and bosutinib modulate preplaque alterations of blood immune markers and neuro-inflammation in Alzheimer's disease models. Neuroscience. 2015;304:316-27.

[54] Lonskaya I, Hebron ML, Desforges NM, Schachter JB, Moussa CE. Nilotinib-induced autophagic changes increase endogenous parkin level and ubiquitination, leading to amyloid clearance. J Mol Med (Berl). 2014;92:373-86.

[55] Luchsinger JA, Perez T, Chang H, Mehta P, Steffener J, Pradabhan G, et al. Metformin in Amnestic Mild Cognitive Impairment: Results of a Pilot Randomized Placebo Controlled Clinical Trial. J Alzheimers Dis. 2016;51:501-14.

[56] Koenig AM, Mechanic-Hamilton D, Xie SX, Combs MF, Cappola AR, Xie L, et al. Effects of the insulin sensitizer metformin in Alzheimer's disease: Pilot data from a randomized placebo-controlled crossover study. Alzheimer Dis Assoc Disord. 2017;31:107.

[57] Son SM, Shin HJ, Byun J, Kook SY, Moon M, Chang YJ, et al. Metformin Facilitates Amyloid-beta Generation by beta- and gamma-Secretases via Autophagy Activation. J Alzheimers Dis. 2016;51:1197208.

[58] Kuhla A, Brichmann E, Ruhlmann C, Thiele R, Meuth L, Vollmar B. Metformin Therapy Aggravates Neurodegenerative Processes in ApoE-/- Mice. J Alzheimers Dis. 2019;68:1415-27.

[59] Sarkar S, Floto RA, Berger Z, Imarisio S, Cordenier A, Pasco M, et al. Lithium induces autophagy by inhibiting inositol monophosphatase. J Cell Biol. 2005;170:1101-11.

[60] Cardenas C, Miller RA, Smith I, Bui T, Molgo J, Muller M, et al. Essential regulation of cell bioenergetics by constitutive InsP3 receptor Ca2+ transfer to mitochondria. Cell. 2010;142:270-83.

[61] Zhang X, Heng X, Li T, Li L, Yang D, Zhang X, et al. Long-term treatment with lithium alleviates memory deficits and reduces amyloid-beta production in an aged Alzheimer's disease transgenic mouse model. J Alzheimers Dis. 2011;24:739-49. 
[62] Chong CM, Ke M, Tan Y, Huang Z, Zhang K, Ai N, et al. Presenilin 1 deficiency suppresses autophagy in human neural stem cells through reducing gamma-secretase-independent ERK/CREB signaling. Cell Death Dis. 2018;9:879.

[63] Luo R, Su LY, Li G, Yang J, Liu Q, Yang LX, et al. Activation of PPARA-mediated autophagy reduces Alzheimer disease-like pathology and cognitive decline in a murine model. Autophagy. 2019:1-18.

[64] Forlenza OV, Radanovic M, Talib LL, Gattaz WF. Clinical and biological effects of long-term lithium treatment in older adults with amnestic mild cognitive impairment: randomised clinical trial. $\mathrm{Br} \mathrm{J}$ Psychiatry. 2019:1-7.

[65] Macdonald A, Briggs K, Poppe M, Higgins A, Velayudhan L, Lovestone S. A feasibility and tolerability study of lithium in Alzheimer's disease. Int J Geriatr Psychiatry. 2008;23:704-11.

[66] Hampel H, Ewers M, Burger K, Annas P, Mortberg A, Bogstedt A, et al. Lithium trial in Alzheimer's disease: a randomized, single-blind, placebo-controlled, multicenter 10-week study. J Clin Psychiatry. 2009;70:922-31.

[67] Williams A, Sarkar S, Cuddon P, Ttofi EK, Saiki S, Siddiqi FH, et al. Novel targets for Huntington's disease in an mTOR-independent autophagy pathway. Nat Chem Biol. 2008;4:295-305.

[68] Ravikumar B, Sarkar S, Davies JE, Futter M, Garcia-Arencibia M, Green-Thompson ZW, et al. Regulation of mammalian autophagy in physiology and pathophysiology. Physiol Rev. 2010;90:1383435.

[69] Underwood BR, Green-Thompson ZW, Pugh PJ, Lazic SE, Mason SL, Griffin J, et al. An open-label study to assess the feasibility and tolerability of rilmenidine for the treatment of Huntington's disease. J Neurol. 2017;264:2457-63.

[70] Coppola G, Chinnathambi S, Lee JJ, Dombroski BA, Baker MC, Soto-Ortolaza Al, et al. Evidence for a role of the rare p.A152T variant in MAPT in increasing the risk for FTD-spectrum and Alzheimer's diseases. Hum Mol Genet. 2012;21:3500-12.

[71] Siddiqi FH, Menzies FM, Lopez A, Stamatakou E, Karabiyik C, Ureshino R, et al. Felodipine induces autophagy in mouse brains with pharmacokinetics amenable to repurposing. Nat Commun. 2019;10:1817.

[72] Medeiros R, Kitazawa M, Chabrier MA, Cheng D, Baglietto-Vargas D, Kling A, et al. Calpain inhibitor A-705253 mitigates Alzheimer's disease-like pathology and cognitive decline in aged 3xTgAD mice. Am J Pathol. 2012;181:616-25.

[73] Rocchi A, Yamamoto S, Ting T, Fan $Y$, Sadleir $K$, Wang $Y$, et al. A Becn1 mutation mediates hyperactive autophagic sequestration of amyloid oligomers and improved cognition in Alzheimer's disease. PLoS Genet. 2017;13:e1006962.

[74] Khandelwal PJ, Herman AM, Hoe HS, Rebeck GW, Moussa CE. Parkin mediates beclin-dependent autophagic clearance of defective mitochondria and ubiquitinated Abeta in AD models. Hum Mol Genet. 2011;20:2091-102.

[75] Nilsson P, Loganathan K, Sekiguchi M, Matsuba Y, Hui K, Tsubuki S, et al. A $\beta$ secretion and plaque formation depend on autophagy. Cell Rep. 2013;5:61-9.

[76] Rao MV, McBrayer MK, Campbell J, Kumar A, Hashim A, Sershen H, et al. Specific calpain inhibition by calpastatin prevents tauopathy and neurodegeneration and restores normal lifespan in tau P301L mice. J Neurosci. 2014;34:9222-34.

[77] Menzies FM, Garcia-Arencibia M, Imarisio S, O'Sullivan NC, Ricketts T, Kent BA, et al. Calpain inhibition mediates autophagy-dependent protection against polyglutamine toxicity. Cell Death Differ. 2015;22:433-44.

[78] Pavel M, Rubinsztein DC. Autophagy Upregulation as a Therapeutic Strategy for Neurodegenerative Diseases. In: Fang FE, Ng BT, editors. Antitumor Potential and other Emerging Medicinal Properties of Natural Compounds. Dordrecht: Springer Netherlands; 2013. p. 227-38.

[79] Polito VA, Li H, Martini-Stoica H, Wang B, Yang L, Xu Y, et al. Selective clearance of aberrant tau proteins and rescue of neurotoxicity by transcription factor EB. EMBO Mol Med. 2014;6:1142-60.

[80] Spillantini MG, Schmidt ML, Lee VM, Trojanowski JQ, Jakes R, Goedert M. Alpha-synuclein in Lewy bodies. Nature. 1997;388:839-40. 
[81] Schöndorf DC, Aureli M, McAllister FE, Hindley CJ, Mayer F, Schmid B, et al. iPSC-derived neurons from GBA1-associated Parkinson's disease patients show autophagic defects and impaired calcium homeostasis. Nat Commun. 2014;5:4028.

[82] Karabiyik C, Lee MJ, Rubinsztein DC. Autophagy impairment in Parkinson's disease. Essays Biochem. 2017;61:711-20.

[83] Feany MB, Bender WW. A Drosophila model of Parkinson's disease. Nature. 2000;404:394-8.

[84] Masliah E, Rockenstein E, Veinbergs I, Mallory M, Hashimoto M, Takeda A, et al. Dopaminergic loss and inclusion body formation in alpha-synuclein mice: implications for neurodegenerative disorders. Science. 2000;287:1265-9.

[85] Ross OA, Braithwaite AT, Skipper LM, Kachergus J, Hulihan MM, Middleton FA, et al. Genomic investigation of alpha-synuclein multiplication and parkinsonism. Ann Neurol. 2008;63:743-50.

[86] Polymeropoulos MH, Lavedan C, Leroy E, Ide SE, Dehejia A, Dutra A, et al. Mutation in the alphasynuclein gene identified in families with Parkinson's disease. Science. 1997;276:2045-7.

[87] Kruger R, Kuhn W, Muller T, Woitalla D, Graeber M, Kosel S, et al. Ala30Pro mutation in the gene encoding alpha-synuclein in Parkinson's disease. Nat Genet. 1998;18:106-8.

[88] Kitada T, Asakawa S, Hattori N, Matsumine H, Yamamura Y, Minoshima S, et al. Mutations in the parkin gene cause autosomal recessive juvenile parkinsonism. Nature. 1998;392:605-8.

[89] li K, Ito H, Tanaka K, Hirano A. Immunocytochemical co-localization of the proteasome in ubiquitinated structures in neurodegenerative diseases and the elderly. J Neuropathol Exp Neurol. 1997;56:125-31.

[90] Vogiatzi T, Xilouri M, Vekrellis K, Stefanis L. Wild type alpha-synuclein is degraded by chaperonemediated autophagy and macroautophagy in neuronal cells. J Biol Chem. 2008;283:23542-56.

[91] Martinez-Vicente M, Talloczy Z, Kaushik S, Massey AC, Mazzulli J, Mosharov EV, et al. Dopaminemodified alpha-synuclein blocks chaperone-mediated autophagy. J Clin Invest. 2008;118:777-88.

[92] Moors T, Paciotti S, Chiasserini D, Calabresi P, Parnetti L, Beccari T, et al. Lysosomal Dysfunction and alpha-Synuclein Aggregation in Parkinson's Disease: Diagnostic Links. Mov Disord. 2016;31:791801.

[93] Yu WH, Dorado B, Figueroa HY, Wang L, Planel E, Cookson MR, et al. Metabolic activity determines efficacy of macroautophagic clearance of pathological oligomeric alpha-synuclein. Am J Pathol. 2009;175:736-47.

[94] Cuervo AM, Stefanis L, Fredenburg R, Lansbury PT, Sulzer D. Impaired degradation of mutant alpha-synuclein by chaperone-mediated autophagy. Science. 2004;305:1292-5.

[95] Tenreiro S, Reimao-Pinto MM, Antas P, Rino J, Wawrzycka D, Macedo D, et al. Phosphorylation modulates clearance of alpha-synuclein inclusions in a yeast model of Parkinson's disease. PLoS Genet. 2014;10:e1004302.

[96] Winslow AR, Chen CW, Corrochano S, Acevedo-Arozena A, Gordon DE, Peden AA, et al. alphaSynuclein impairs macroautophagy: implications for Parkinson's disease. J Cell Biol. 2010;190:102337.

[97] Zavodszky E, Seaman MN, Moreau K, Jimenez-Sanchez M, Breusegem SY, Harbour ME, et al. Mutation in VPS35 associated with Parkinson's disease impairs WASH complex association and inhibits autophagy. Nat Commun. 2014;5:3828.

[98] Tang FL, Erion JR, Tian Y, Liu W, Yin DM, Ye J, et al. VPS35 in Dopamine Neurons Is Required for Endosome-to-Golgi Retrieval of Lamp2a, a Receptor of Chaperone-Mediated Autophagy That Is Critical for alpha-Synuclein Degradation and Prevention of Pathogenesis of Parkinson's Disease. J Neurosci. 2015;35:10613-28.

[99] Lonskaya I, Hebron ML, Algarzae NK, Desforges N, Moussa CE. Decreased parkin solubility is associated with impairment of autophagy in the nigrostriatum of sporadic Parkinson's disease. Neuroscience. 2013;232:90-105.

[100] Tanik SA, Schultheiss CE, Volpicelli-Daley LA, Brunden KR, Lee VM. Lewy body-like alphasynuclein aggregates resist degradation and impair macroautophagy. J Biol Chem. 2013;288:15194210. 
[101] Jenner P, Olanow CW. Oxidative stress and the pathogenesis of Parkinson's disease. Neurology. 1996;47:S161-70.

[102] Chen L, Xie Z, Turkson S, Zhuang X. A53T human alpha-synuclein overexpression in transgenic mice induces pervasive mitochondria macroautophagy defects preceding dopamine neuron degeneration. J Neurosci. 2015;35:890-905.

[103] Bultron G, Kacena K, Pearson D, Boxer M, Yang R, Sathe S, et al. The risk of Parkinson's disease in type 1 Gaucher disease. J Inherit Metab Dis. 2010;33:167-73.

[104] Bento CF, Ashkenazi A, Jimenez-Sanchez M, Rubinsztein DC. The Parkinson's disease-associated genes ATP13A2 and SYT11 regulate autophagy via a common pathway. Nat Commun. 2016;7:11803.

[105] Bove J, Martinez-Vicente M, Vila M. Fighting neurodegeneration with rapamycin: mechanistic insights. Nat Rev Neurosci. 2011;12:437-52.

[106] Dehay B, Bove J, Rodriguez-Muela N, Perier C, Recasens A, Boya P, et al. Pathogenic lysosomal depletion in Parkinson's disease. J Neurosci. 2010;30:12535-44.

[107] Crews L, Spencer B, Desplats P, Patrick C, Paulino A, Rockenstein E, et al. Selective molecular alterations in the autophagy pathway in patients with Lewy body disease and in models of alphasynucleinopathy. PLoS One. 2010;5:e9313.

[108] Malagelada C, Jin ZH, Jackson-Lewis V, Przedborski S, Greene LA. Rapamycin protects against neuron death in in vitro and in vivo models of Parkinson's disease. J Neurosci. 2010;30:1166-75.

[109] Bai X, Wey MC, Fernandez E, Hart MJ, Gelfond J, Bokov AF, et al. Rapamycin improves motor function, reduces 4-hydroxynonenal adducted protein in brain, and attenuates synaptic injury in a mouse model of synucleinopathy. Pathobiol Aging Age Relat Dis. 2015;5:28743.

[110] Kim YC, Guan KL. MTOR: A pharmacologic target for autophagy regulation. J Clin Invest2015.

[111] Renna M, Bento CF, Fleming A, Menzies FM, Siddiqi FH, Ravikumar B, et al. IGF-1 receptor antagonism inhibits autophagy. Hum Mol Genet. 2013;22:4528-44.

[112] Sarkar S, Perlstein EO, Imarisio S, Pineau S, Cordenier A, Maglathlin RL, et al. Small molecules enhance autophagy and reduce toxicity in Huntington's disease models. Nat Chem Biol. 2007;3:3318.

[113] Sarkar S, Rubinsztein DC. Small molecule enhancers of autophagy for neurodegenerative diseases. Mol Biosyst. 2008;4:895-901.

[114] Sarkar S, Chigurupati S, Raymick J, Mann D, Bowyer JF, Schmitt T, et al. Neuroprotective effect of the chemical chaperone, trehalose in a chronic MPTP-induced Parkinson's disease mouse model. Neurotoxicology. 2014;44:250-62.

[115] He Q, Koprich JB, Wang Y, Yu WB, Xiao BG, Brotchie JM, et al. Treatment with Trehalose Prevents Behavioral and Neurochemical Deficits Produced in an AAV alpha-Synuclein Rat Model of Parkinson's Disease. Mol Neurobiol. 2016;53:2258-68.

[116] Palmieri M, Pal R, Nelvagal HR, Lotfi P, Stinnett GR, Seymour ML, et al. mTORC1-independent TFEB activation via Akt inhibition promotes cellular clearance in neurodegenerative storage diseases. Nat Commun. 2017;8:14338.

[117] Pupyshev AB, Tikhonova MA, Akopyan AA, Tenditnik MV, Dubrovina NI, Korolenko TA. Therapeutic activation of autophagy by combined treatment with rapamycin and trehalose in a mouse MPTP-induced model of Parkinson's disease. Pharmacol Biochem Behav. 2019;177:1-11.

[118] Dulovic M, Jovanovic M, Xilouri M, Stefanis L, Harhaji-Trajkovic L, Kravic-Stevovic T, et al. The protective role of AMP-activated protein kinase in alpha-synuclein neurotoxicity in vitro. Neurobiol Dis. 2014;63:1-11.

[119] Ng CH, Guan MS, Koh C, Ouyang X, Yu F, Tan EK, et al. AMP kinase activation mitigates dopaminergic dysfunction and mitochondrial abnormalities in Drosophila models of Parkinson's disease. J Neurosci. 2012;32:14311-7.

[120] Patil SP, Jain PD, Ghumatkar PJ, Tambe R, Sathaye S. Neuroprotective effect of metformin in MPTP-induced Parkinson's disease in mice. Neuroscience. 2014;277:747-54.

[121] Yu HC, Lin CS, Tai WT, Liu CY, Shiau CW, Chen KF. Nilotinib induces autophagy in hepatocellular carcinoma through AMPK activation. J Biol Chem. 2013;288:18249-59. 
[122] Hebron ML, Lonskaya I, Moussa CE. Nilotinib reverses loss of dopamine neurons and improves motor behavior via autophagic degradation of alpha-synuclein in Parkinson's disease models. Hum Mol Genet. 2013;22:3315-28.

[123] Karuppagounder SS, Brahmachari S, Lee Y, Dawson VL, Dawson TM, Ko HS. The c-Abl inhibitor, nilotinib, protects dopaminergic neurons in a preclinical animal model of Parkinson's disease. Sci Rep. 2014;4:4874.

[124] Simuni T, Fiske B, Merchant K, Coffey C, Matthews H, Wyse RK, et al. NILO-PD: A Phase 2A Study of Nilotinib in Patients with Advanced and Early Parkinson's Disease: Study Design and Status Update (P3. 8-035). AAN Enterprises; 2019.

[125] Ferretta A, Gaballo A, Tanzarella P, Piccoli C, Capitanio N, Nico B, et al. Effect of resveratrol on mitochondrial function: implications in parkin-associated familiar Parkinson's disease. Biochim Biophys Acta. 2014;1842:902-15.

[126] Park SJ, Ahmad F, Philp A, Baar K, Williams T, Luo H, et al. Resveratrol ameliorates aging-related metabolic phenotypes by inhibiting cAMP phosphodiesterases. Cell. 2012;148:421-33.

[127] Wu Y, Li X, Zhu JX, Xie W, Le W, Fan Z, et al. Resveratrol-activated AMPK/SIRT1/autophagy in cellular models of Parkinson's disease. Neurosignals. 2011;19:163-74.

[128] Khan MM, Ahmad A, Ishrat T, Khan MB, Hoda MN, Khuwaja G, et al. Resveratrol attenuates 6hydroxydopamine-induced oxidative damage and dopamine depletion in rat model of Parkinson's disease. Brain Res. 2010;1328:139-51.

[129] Jin F, Wu Q, Lu YF, Gong QH, Shi JS. Neuroprotective effect of resveratrol on 6-OHDA-induced Parkinson's disease in rats. Eur J Pharmacol. 2008;600:78-82.

[130] Blanchet J, Longpre F, Bureau G, Morissette M, DiPaolo T, Bronchti G, et al. Resveratrol, a red wine polyphenol, protects dopaminergic neurons in MPTP-treated mice. Prog Neuropsychopharmacol Biol Psychiatry. 2008;32:1243-50.

[131] Lu JH, Tan JQ, Durairajan SS, Liu LF, Zhang ZH, Ma L, et al. Isorhynchophylline, a natural alkaloid, promotes the degradation of alpha-synuclein in neuronal cells via inducing autophagy. Autophagy. 2012;8:98-108.

[132] Wang K, Huang J, Xie W, Huang L, Zhong C, Chen Z. Beclin1 and HMGB1 ameliorate the alphasynuclein-mediated autophagy inhibition in PC12 cells. Diagn Pathol. 2016;11:15.

[133] Song JX, Lu JH, Liu LF, Chen LL, Durairajan SS, Yue Z, et al. HMGB1 is involved in autophagy inhibition caused by SNCA/alpha-synuclein overexpression: a process modulated by the natural autophagy inducer corynoxine B. Autophagy. 2014;10:144-54.

[134] Chen LL, Song JX, Lu JH, Yuan ZW, Liu LF, Durairajan SS, et al. Corynoxine, a natural autophagy enhancer, promotes the clearance of alpha-synuclein via Akt/mTOR pathway. J Neuroimmune Pharmacol. 2014;9:380-7.

[135] Hou L, Xiong N, Liu L, Huang J, Han C, Zhang G, et al. Lithium protects dopaminergic cells from rotenone toxicity via autophagy enhancement. BMC Neurosci. 2015;16:82.

[136] Lieu CA, Dewey CM, Chinta SJ, Rane A, Rajagopalan S, Batir S, et al. Lithium prevents parkinsonian behavioral and striatal phenotypes in an aged parkin mutant transgenic mouse model. Brain Res. 2014;1591:111-7.

[137] Duka T, Duka V, Joyce JN, Sidhu A. Alpha-Synuclein contributes to GSK-3beta-catalyzed Tau phosphorylation in Parkinson's disease models. FASEB J. 2009;23:2820-30.

[138] Xiong N, Jia M, Chen C, Xiong J, Zhang Z, Huang J, et al. Potential autophagy enhancers attenuate rotenone-induced toxicity in SH-SY5Y. Neuroscience. 2011;199:292-302.

[139] Sarkar S, Ravikumar B, Floto RA, Rubinsztein DC. Rapamycin and mTOR-independent autophagy inducers ameliorate toxicity of polyglutamine-expanded huntingtin and related proteinopathies. Cell Death Differ. 2009;16:46-56.

[140] Li XZ, Chen XP, Zhao K, Bai LM, Zhang H, Zhou XP. Therapeutic effects of valproate combined with lithium carbonate on MPTP-induced parkinsonism in mice: possible mediation through enhanced autophagy. Int J Neurosci. 2013;123:73-9. 
[141] Martini-Stoica H, Xu Y, Ballabio A, Zheng H. The Autophagy-Lysosomal Pathway in Neurodegeneration: A TFEB Perspective. Trends Neurosci. 2016;39:221-34.

[142] Decressac M, Mattsson B, Weikop P, Lundblad M, Jakobsson J, Bjorklund A. TFEB-mediated autophagy rescues midbrain dopamine neurons from alpha-synuclein toxicity. Proc Natl Acad Sci U S A. 2013;110:E1817-26.

[143] Spencer B, Potkar R, Trejo M, Rockenstein E, Patrick C, Gindi R, et al. Beclin 1 gene transfer activates autophagy and ameliorates the neurodegenerative pathology in alpha-synuclein models of Parkinson's and Lewy body diseases. J Neurosci. 2009;29:13578-88.

[144] Fan HC, Ho LI, Chi CS, Chen SJ, Peng GS, Chan TM, et al. Polyglutamine (PolyQ) diseases: genetics to treatments. Cell Transplant. 2014;23:441-58.

[145] Martinez-Vicente M, Talloczy Z, Wong E, Tang GM, Koga H, Kaushik S, et al. Cargo recognition failure is responsible for inefficient autophagy in Huntington's disease. Nature Neuroscience. 2010;13:567-U74.

[146] Rui YN, Xu Z, Patel B, Chen ZH, Chen DS, Tito A, et al. Huntingtin functions as a scaffold for selective macroautophagy. Nature Cell Biology. 2015;17:262-+.

[147] Ochaba J, Lukacsovich T, Csikos G, Zheng SQ, Margulis J, Salazar L, et al. Potential function for the Huntingtin protein as a scaffold for selective autophagy. Proc Natl Acad Sci U S A. 2014;111:1688994.

[148] Zheng S, Clabough EB, Sarkar S, Futter M, Rubinsztein DC, Zeitlin SO. Deletion of the huntingtin polyglutamine stretch enhances neuronal autophagy and longevity in mice. PLoS Genet. 2010;6:e1000838.

[149] Gunawardena S, Her LS, Brusch RG, Laymon RA, Niesman IR, Gordesky-Gold B, et al. Disruption of axonal transport by loss of huntingtin or expression of pathogenic polyQ proteins in Drosophila. Neuron. 2003;40:25-40.

[150] Maday S, Wallace KE, Holzbaur EL. Autophagosomes initiate distally and mature during transport toward the cell soma in primary neurons. J Cell Biol. 2012;196:407-17.

[151] Ravikumar B, Acevedo-Arozena A, Imarisio S, Berger Z, Vacher C, O'Kane CJ, et al. Dynein mutations impair autophagic clearance of aggregate-prone proteins. Nat Genet. 2005;37:771-6.

[152] Szebenyi G, Morfini GA, Babcock A, Gould M, Selkoe K, Stenoien DL, et al. Neuropathogenic forms of huntingtin and androgen receptor inhibit fast axonal transport. Neuron. 2003;40:41-52.

[153] Wong YC, Holzbaur ELF. The Regulation of Autophagosome Dynamics by Huntingtin and HAP1 Is Disrupted by Expression of Mutant Huntingtin, Leading to Defective Cargo Degradation. Journal of Neuroscience. 2014;34:1293-305.

[154] Caviston JP, Ross JL, Antony SM, Tokito M, Holzbaur EL. Huntingtin facilitates dynein/dynactinmediated vesicle transport. Proc Natl Acad Sci U S A. 2007;104:10045-50.

[155] Kang R, Zeh HJ, Lotze MT, Tang D. The Beclin 1 network regulates autophagy and apoptosis. Cell Death Differ. 2011;18:571-80.

[156] Cortes CJ, Miranda HC, Frankowski H, Batlevi Y, Young JE, Le A, et al. Polyglutamine-expanded androgen receptor interferes with TFEB to elicit autophagy defects in SBMA. Nat Neurosci. 2014;17:1180-9.

[157] Napolitano G, Ballabio A. TFEB at a glance. J Cell Sci. 2016;129:2475-81.

[158] Baron O, Boudi A, Dias C, Schilling M, Nolle A, Vizcay-Barrena G, et al. Stall in Canonical Autophagy-Lysosome Pathways Prompts Nucleophagy-Based Nuclear Breakdown in Neurodegeneration. Curr Biol. 2017;27:3626-42 e6.

[159] Nisoli I, Chauvin J, Napoletano F, Calamita P, Zanin V, Fanto M, et al. Neurodegeneration by polyglutamine Atrophin is not rescued by induction of autophagy. Cell Death Differ. 2010;17:1577.

[160] Shao J, Diamond MI. Polyglutamine diseases: emerging concepts in pathogenesis and therapy. Hum Mol Genet. 2007;16 Spec No. 2:R115-23.

[161] Ravikumar B, Duden R, Rubinsztein DC. Aggregate-prone proteins with polyglutamine and polyalanine expansions are degraded by autophagy. Hum Mol Genet. 2002;11:1107-17. 
[162] Verhoef LG, Lindsten K, Masucci MG, Dantuma NP. Aggregate formation inhibits proteasomal degradation of polyglutamine proteins. Hum Mol Genet. 2002;11:2689-700.

[163] Tanaka M, Machida Y, Niu S, Ikeda T, Jana NR, Doi H, et al. Trehalose alleviates polyglutaminemediated pathology in a mouse model of Huntington disease. Nat Med. 2004;10:148-54.

[164] Sarkar S, Krishna G, Imarisio S, Saiki S, O'Kane CJ, Rubinsztein DC. A rational mechanism for combination treatment of Huntington's disease using lithium and rapamycin. Hum Mol Genet. 2007; 17:170-8.

[165] Fleming A, Noda T, Yoshimori T, Rubinsztein DC. Chemical modulators of autophagy as biological probes and potential therapeutics. Nat Chem Biol. 2011;7:9-17.

[166] Sarkar S, Korolchuk VI, Renna M, Imarisio S, Fleming A, Williams A, et al. Complex inhibitory effects of nitric oxide on autophagy. Mol Cell. 2011;43:19-32.

[167] Tsvetkov AS, Miller J, Arrasate M, Wong JS, Pleiss MA, Finkbeiner S. A small-molecule scaffold induces autophagy in primary neurons and protects against toxicity in a Huntington disease model. Proc Natl Acad Sci U S A. 2010;107:16982-7.

[168] Abd-Elrahman KS, Hamilton A, Hutchinson SR, Liu F, Russell RC, Ferguson SSG. mGluR5 antagonism increases autophagy and prevents disease progression in the zQ175 mouse model of Huntington's disease. Sci Signal. 2017;10:eaan6387.

[169] Katsuno M, Adachi H, Kume A, Li M, Nakagomi Y, Niwa H, et al. Testosterone reduction prevents phenotypic expression in a transgenic mouse model of spinal and bulbar muscular atrophy. Neuron. 2002;35:843-54.

[170] Takeyama K, Ito S, Yamamoto A, Tanimoto H, Furutani T, Kanuka H, et al. Androgen-dependent neurodegeneration by polyglutamine-expanded human androgen receptor in Drosophila. Neuron. 2002;35:855-64.

[171] Iwata A, Christianson JC, Bucci M, Ellerby LM, Nukina N, Forno LS, et al. Increased susceptibility of cytoplasmic over nuclear polyglutamine aggregates to autophagic degradation. Proc Natl Acad Sci U S A. 2005;102:13135-40.

[172] Baniahmad A. Inhibition of the Androgen Receptor by Antiandrogens in Spinobulbar Muscle Atrophy. J Mol Neurosci. 2016;58:343-7.

[173] Rusmini P, Bolzoni E, Crippa V, Onesto E, Sau D, Galbiati M, et al. Proteasomal and autophagic degradative activities in spinal and bulbar muscular atrophy. Neurobiol Dis. 2010;40:361-9.

[174] Giorgetti E, Rusmini P, Crippa V, Cristofani R, Boncoraglio A, Cicardi ME, et al. Synergic prodegradative activity of Bicalutamide and trehalose on the mutant androgen receptor responsible for spinal and bulbar muscular atrophy. Hum Mol Genet. 2015;24:64-75.

[175] Walter C, Clemens LE, Muller AJ, Fallier-Becker P, Proikas-Cezanne T, Riess O, et al. Activation of AMPK-induced autophagy ameliorates Huntington disease pathology in vitro. Neuropharmacology. 2016;108:24-38.

[176] Ravikumar B, Imarisio S, Sarkar S, O'Kane CJ, Rubinsztein DC. Rab5 modulates aggregation and toxicity of mutant huntingtin through macroautophagy in cell and fly models of Huntington disease. J Cell Sci. 2008;121:1649-60.

[177] Vidal RL, Figueroa A, Court FA, Thielen P, Molina C, Wirth C, et al. Targeting the UPR transcription factor XBP1 protects against Huntington's disease through the regulation of FoxO1 and autophagy. Hum Mol Genet. 2012;21:2245-62.

[178] Tsunemi T, Ashe TD, Morrison BE, Soriano KR, Au J, Roque RA, et al. PGC-1alpha rescues Huntington's disease proteotoxicity by preventing oxidative stress and promoting TFEB function. Sci Transl Med. 2012;4:142ra97.

[179] Aron R, Pellegrini P, Green EW, Maddison DC, Opoku-Nsiah K, Wong JS, et al. Deubiquitinase Usp12 functions noncatalytically to induce autophagy and confer neuroprotection in models of Huntington's disease. Nat Commun. 2018;9:3191.

[180] Khalil B, El Fissi N, Aouane A, Cabirol-Pol MJ, Rival T, Lievens JC. PINK1-induced mitophagy promotes neuroprotection in Huntington's disease. Cell Death Dis. 2015;6:e1617. 
[181] Nascimento-Ferreira I, Santos-Ferreira T, Sousa-Ferreira L, Auregan G, Onofre I, Alves S, et al. Overexpression of the autophagic beclin-1 protein clears mutant ataxin-3 and alleviates MachadoJoseph disease. Brain. 2011;134:1400-15.

[182] Nascimento-Ferreira I, Nobrega C, Vasconcelos-Ferreira A, Onofre I, Albuquerque D, Aveleira C, et al. Beclin 1 mitigates motor and neuropathological deficits in genetic mouse models of MachadoJoseph disease. Brain. 2013;136:2173-88.

[183] Turner MR, Hardiman O, Benatar M, Brooks BR, Chio A, de Carvalho M, et al. Controversies and priorities in amyotrophic lateral sclerosis. Lancet Neurol. 2013;12:310-22.

[184] Rosen DR, Siddique T, Patterson D, Figlewicz DA, Sapp P, Hentati A, et al. Mutations in Cu/Zn superoxide dismutase gene are associated with familial amyotrophic lateral sclerosis. Nature. 1993;362:59.

[185] Vance C, Rogelj B, Hortobagyi T, De Vos KJ, Nishimura AL, Sreedharan J, et al. Mutations in FUS, an RNA processing protein, cause familial amyotrophic lateral sclerosis type 6 . Science. 2009;323:1208-11.

[186] Sreedharan J, Blair IP, Tripathi VB, Hu X, Vance C, Rogelj B, et al. TDP-43 mutations in familial and sporadic amyotrophic lateral sclerosis. Science. 2008;319:1668-72.

[187] Fecto F, Yan J, Vemula SP, Liu E, Yang Y, Chen W, et al. SQSTM1 mutations in familial and sporadic amyotrophic lateral sclerosis. Arch Neurol. 2011;68:1440-6.

[188] Teyssou E, Takeda T, Lebon V, Boillee S, Doukoure B, Bataillon G, et al. Mutations in SQSTM1 encoding p62 in amyotrophic lateral sclerosis: genetics and neuropathology. Acta Neuropathol. 2013;125:511-22.

[189] Maruyama $\mathrm{H}$, Morino $\mathrm{H}$, Ito $\mathrm{H}$, Izumi $\mathrm{Y}$, Kato $\mathrm{H}$, Watanabe $\mathrm{Y}$, et al. Mutations of optineurin in amyotrophic lateral sclerosis. Nature. 2010;465:223-6.

[190] Johnson JO, Mandrioli J, Benatar M, Abramzon Y, Van Deerlin VM, Trojanowski JQ, et al. Exome Sequencing Reveals VCP Mutations as a Cause of Familial ALS. Neuron. 2010;68:857-64.

[191] Freischmidt A, Wieland T, Richter B, Ruf W, Schaeffer V, Muller K, et al. Haploinsufficiency of TBK1 causes familial ALS and fronto-temporal dementia. Nat Neurosci. 2015;18:631-6.

[192] Deng HX, Chen W, Hong ST, Boycott KM, Gorrie GH, Siddique N, et al. Mutations in UBQLN2 cause dominant X-linked juvenile and adult-onset ALS and ALS/dementia. Nature. 2011;477:211-5.

[193] Puls I, Jonnakuty C, LaMonte BH, Holzbaur EL, Tokito M, Mann E, et al. Mutant dynactin in motor neuron disease. Nat Genet. 2003;33:455-6.

[194] Hadano S, Hand CK, Osuga H, Yanagisawa Y, Otomo A, Devon RS, et al. A gene encoding a putative GTPase regulator is mutated in familial amyotrophic lateral sclerosis 2. Nat Genet. 2001;29:166.

[195] Wu CH, Fallini C, Ticozzi N, Keagle PJ, Sapp PC, Piotrowska K, et al. Mutations in the profilin 1 gene cause familial amyotrophic lateral sclerosis. Nature. 2012;488:499-503.

[196] Parkinson N, Ince PG, Smith MO, Highley R, Skibinski G, Andersen PM, et al. ALS phenotypes with mutations in CHMP2B (charged multivesicular body protein 2B). Neurology. 2006;67:1074-7.

[197] Cox LE, Ferraiuolo L, Goodall EF, Heath PR, Higginbottom A, Mortiboys H, et al. Mutations in CHMP2B in lower motor neuron predominant amyotrophic lateral sclerosis (ALS). PLoS One. 2010;5:e9872.

[198] Chow CY, Landers JE, Bergren SK, Sapp PC, Grant AE, Jones JM, et al. Deleterious variants of FIG4, a phosphoinositide phosphatase, in patients with ALS. Am J Hum Genet. 2009;84:85-8.

[199] DeJesus-Hernandez M, Mackenzie IR, Boeve BF, Boxer AL, Baker M, Rutherford NJ, et al. Expanded GGGGCC hexanucleotide repeat in noncoding region of C9ORF72 causes chromosome 9plinked FTD and ALS. Neuron. 2011;72:245-56.

[200] Taylor JP, Brown RH, Jr., Cleveland DW. Decoding ALS: from genes to mechanism. Nature. 2016;539:197-206.

[201] Bruijn LI, Houseweart MK, Kato S, Anderson KL, Anderson SD, Ohama E, et al. Aggregation and motor neuron toxicity of an ALS-linked SOD1 mutant independent from wild-type SOD1. Science. 1998;281:1851-4. 
[202] Scotter EL, Chen H-J, Shaw CE. TDP-43 proteinopathy and ALS: insights into disease mechanisms and therapeutic targets. Neurotherapeutics. 2015;12:352-63.

[203] Van Deerlin VM, Leverenz JB, Bekris LM, Bird TD, Yuan W, Elman LB, et al. TARDBP mutations in amyotrophic lateral sclerosis with TDP-43 neuropathology: a genetic and histopathological analysis. Lancet Neurol. 2008;7:409-16.

[204] Johansen T, Lamark T. Selective autophagy mediated by autophagic adapter proteins. Autophagy. 2011;7:279-96.

[205] Zaffagnini G, Martens S. Mechanisms of Selective Autophagy. J Mol Biol. 2016;428:1714-24.

[206] Goode A, Butler K, Long J, Cavey J, Scott D, Shaw B, et al. Defective recognition of LC3B by mutant SQSTM1/p62 implicates impairment of autophagy as a pathogenic mechanism in ALS-FTLD. Autophagy. 2016;12:1094-104.

[207] Fifita JA, Williams KL, Sundaramoorthy V, McCann EP, Nicholson GA, Atkin JD, et al. A novel amyotrophic lateral sclerosis mutation in OPTN induces ER stress and Golgi fragmentation in vitro. Amyotroph Lateral Scler Frontotemporal Degener. 2017;18:126-33.

[208] Korac J, Schaeffer V, Kovacevic I, Clement AM, Jungblut B, Behl C, et al. Ubiquitin-independent function of optineurin in autophagic clearance of protein aggregates. J Cell Sci. 2013;126:580-92.

[209] Shen WC, Li HY, Chen GC, Chern Y, Tu PH. Mutations in the ubiquitin-binding domain of OPTN/optineurin interfere with autophagy-mediated degradation of misfolded proteins by a dominant-negative mechanism. Autophagy. 2015;11:685-700.

[210] Sundaramoorthy V, Walker AK, Tan V, Fifita JA, Mccann EP, Williams KL, et al. Defects in optineurin- and myosin VI-mediated cellular trafficking in amyotrophic lateral sclerosis. Hum Mol Genet. 2015;24:3830-46.

[211] Wu Q, Liu M, Huang C, Liu X, Huang B, Li N, et al. Pathogenic Ubqln2 gains toxic properties to induce neuron death. Acta Neuropathol. 2015;129:417-28.

[212] Topp JD, Gray NW, Gerard RD, Horazdovsky BF. Alsin is a Rab5 and Rac1 guanine nucleotide exchange factor. J Biol Chem. 2004;279:24612-23.

[213] Hadano S, Otomo A, Kunita R, Suzuki-Utsunomiya K, Akatsuka A, Koike M, et al. Loss of ALS2/Alsin exacerbates motor dysfunction in a SOD1H46R-expressing mouse ALS model by disturbing endolysosomal trafficking. PloS One. 2010;5:e9805.

[214] Hadano S, Mitsui S, Pan L, Otomo A, Kubo M, Sato K, et al. Functional links between SQSTM1 and ALS2 in the pathogenesis of ALS: cumulative impact on the protection against mutant SOD1mediated motor dysfunction in mice. Hum Mol Genet. 2016;25:3321-40.

[215] Morimoto N, Nagai M, Ohta Y, Miyazaki K, Kurata T, Morimoto M, et al. Increased autophagy in transgenic mice with a G93A mutant SOD1 gene. Brain Res. 2007;1167:112-7.

[216] Xie Y, Zhou B, Lin MY, Wang S, Foust KD, Sheng ZH. Endolysosomal Deficits Augment Mitochondria Pathology in Spinal Motor Neurons of Asymptomatic fALS Mice. Neuron. 2015;87:35570.

[217] Bose JK, Huang CC, Shen CK. Regulation of autophagy by neuropathological protein TDP-43. J Biol Chem. 2011;286:44441-8.

[218] Zhang YJ, Gendron TF, Grima JC, Sasaguri H, Jansen-West K, Xu YF, et al. C9ORF72 poly(GA) aggregates sequester and impair HR23 and nucleocytoplasmic transport proteins. Nat Neurosci. 2016;19:668-77.

[219] Mori K, Weng SM, Arzberger T, May S, Rentzsch K, Kremmer E, et al. The C9orf72 GGGGCC Repeat Is Translated into Aggregating Dipeptide-Repeat Proteins in FTLD/ALS. Science. 2013;339:1335-8.

[220] Yamakawa M, Ito D, Honda T, Kubo K, Noda M, Nakajima K, et al. Characterization of the dipeptide repeat protein in the molecular pathogenesis of c9FTD/ALS. Hum Mol Genet. 2015;24:163045.

[221] Ugolino J, Ji YJ, Conchina K, Chu J, Nirujogi RS, Pandey A, et al. Loss of C9orf72 Enhances Autophagic Activity via Deregulated mTOR and TFEB Signaling. PLoS Genet. 2016;12:e1006443. 
[222] Nassif M, Woehlbier U, Manque PA. The Enigmatic Role of C9ORF72 in Autophagy. Front Neurosci. 2017;11:442.

[223] Kabuta T, Suzuki Y, Wada K. Degradation of amyotrophic lateral sclerosis-linked mutant Cu,Znsuperoxide dismutase proteins by macroautophagy and the proteasome. J Biol Chem. 2006;281:30524-33.

[224] Ueda T, Ito T, Kurita H, Inden M, Hozumi I. p-Coumaric Acid Has Protective Effects against Mutant Copper-Zinc Superoxide Dismutase 1 via the Activation of Autophagy in N2a Cells. Int J Mol Sci. 2019;20:2942.

[225] Zhang X, Li L, Chen S, Yang D, Wang Y, Zhang X, et al. Rapamycin treatment augments motor neuron degeneration in SOD1G93A mouse model of amyotrophic lateral sclerosis. Autophagy. 2011;7:412-25.

[226] Zhang X, Chen S, Lu K, Wang F, Deng J, Xu Z, et al. Verapamil Ameliorates Motor Neuron Degeneration and Improves Lifespan in the SOD1 G93A Mouse Model of ALS by Enhancing Autophagic Flux. Aging Dis. 2019:0.

[227] Castillo K, Nassif M, Valenzuela V, Rojas F, Matus S, Mercado G, et al. Trehalose delays the progression of amyotrophic lateral sclerosis by enhancing autophagy in motoneurons. Autophagy. 2013;9:1308-20.

[228] Li Y, Guo Y, Wang X, Yu X, Duan W, Hong K, et al. Trehalose decreases mutant SOD1 expression and alleviates motor deficiency in early but not end-stage amyotrophic lateral sclerosis in a SOD1G93A mouse model. Neuroscience. 2015;298:12-25.

[229] Wang X, Fan H, Ying Z, Li B, Wang H, Wang G. Degradation of TDP-43 and its pathogenic form by autophagy and the ubiquitin-proteasome system. Neurosci Lett. 2010;469:112-6.

[230] Wang IF, Tsai KJ, Shen CK. Autophagy activation ameliorates neuronal pathogenesis of FTLD-U mice: a new light for treatment of TARDBP/TDP-43 proteinopathies. Autophagy. 2013;9:239-40.

[231] Marrone L, Drexler HCA, Wang J, Tripathi P, Distler T, Heisterkamp P, et al. FUS pathology in ALS is linked to alterations in multiple ALS-associated proteins and rescued by drugs stimulating autophagy. Acta Neuropathol. 2019;138:67-84.

[232] Wang IF, Guo BS, Liu YC, Wu CC, Yang CH, Tsai KJ, et al. Autophagy activators rescue and alleviate pathogenesis of a mouse model with proteinopathies of the TAR DNA-binding protein 43. Proc Natl Acad Sci U S A. 2012;109:15024-9.

[233] Barmada SJ, Serio A, Arjun A, Bilican B, Daub A, Ando DM, et al. Autophagy induction enhances TDP43 turnover and survival in neuronal ALS models. Nat Chem Biol. 2014;10:677-85.

[234] Fang Y, Vilella-Bach M, Bachmann R, Flanigan A, Chen J. Phosphatidic acid-mediated mitogenic activation of mTOR signaling. Science. 2001;294:1942-5.

[235] Xia Q, Wang H, Hao Z, Fu C, Hu Q, Gao F, et al. TDP-43 loss of function increases TFEB activity and blocks autophagosome-lysosome fusion. EMBO J. 2016;35:121-42.

[236] Hetz C, Thielen P, Matus S, Nassif M, Court F, Kiffin R, et al. XBP-1 deficiency in the nervous system protects against amyotrophic lateral sclerosis by increasing autophagy. Genes Dev. 2009;23:2294-306.

[237] Rudnick ND, Griffey CJ, Guarnieri P, Gerbino V, Wang X, Piersaint JA, et al. Distinct roles for motor neuron autophagy early and late in the SOD1(G93A) mouse model of ALS. Proc Natl Acad Sci U S A. 2017;114:E8294-E303.

[238] Nassif M, Valenzuela V, Rojas-Rivera D, Vidal R, Matus S, Castillo K, et al. Pathogenic role of BECN1/Beclin 1 in the development of amyotrophic lateral sclerosis. Autophagy. 2014;10:1256-71.

[239] Tokuda E, Brannstrom T, Andersen PM, Marklund SL. Low autophagy capacity implicated in motor system vulnerability to mutant superoxide dismutase. Acta Neuropathol Commun. 2016;4:6.

[240] Soo KY, Sultana J, King AE, Atkinson RAK, Warraich ST, Sundaramoorthy V, et al. ALS-associated mutant FUS inhibits macroautophagy which is restored by overexpression of Rab1. Cell Death Discov. 2015;1:15030. 


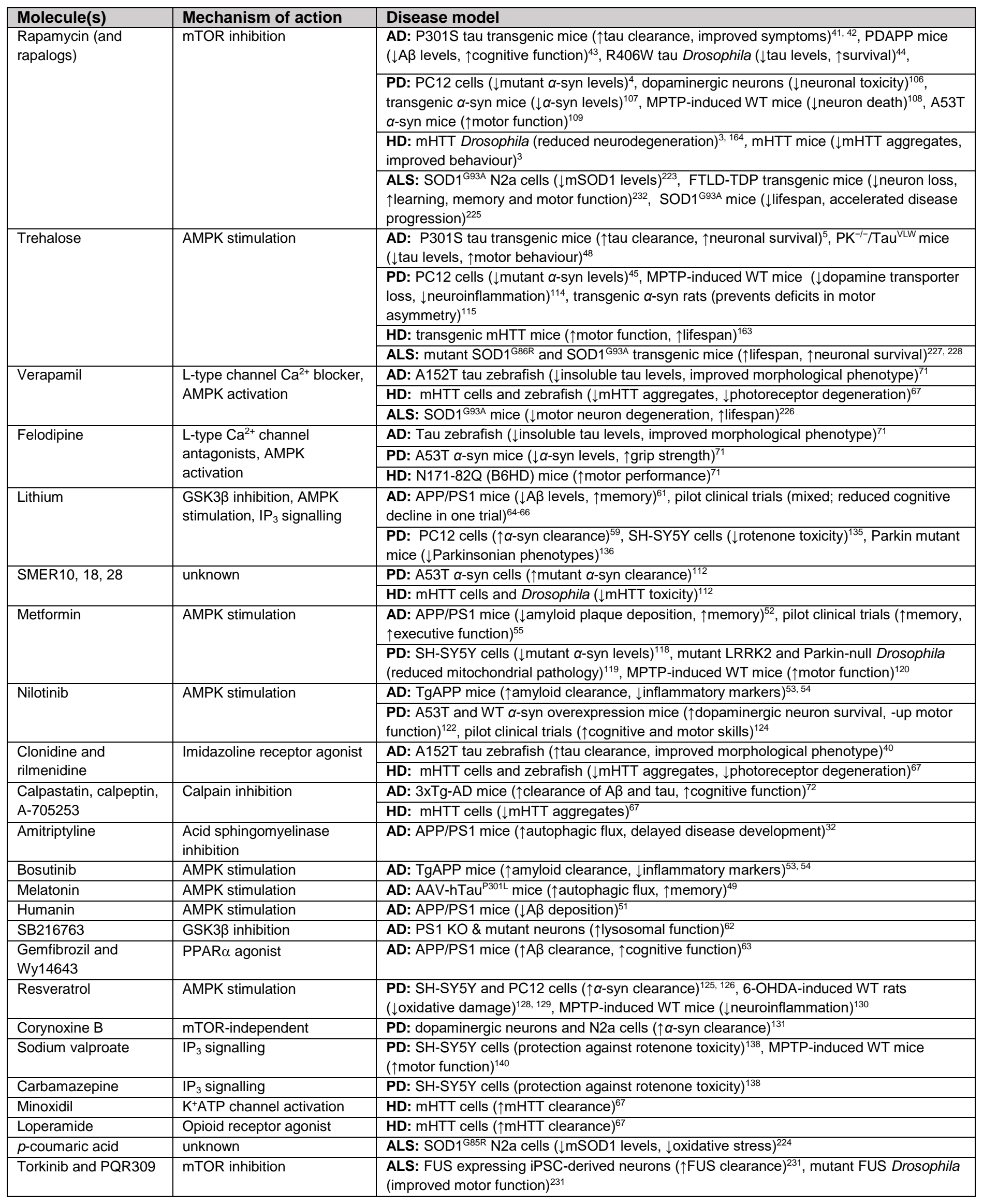




\section{Upstream regulation}

AR (SBMA)

ATN1 (DRPLA)

C9orf72 (ALS)

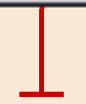

Signalling and activation (mTORC1, TFEB, AMPK, ULK1)

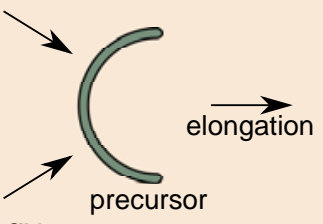

Autophagy machinery

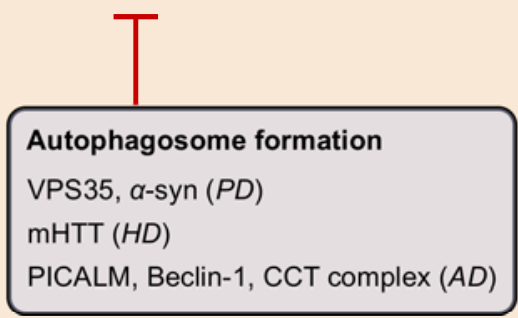

\section{Lysosomal function}

ATP13A2, SYT11, GBA, a-syn, VPS35 (PD) CCT complex, PS-1, APOE4 (AD) ATN1 (DRPLA)

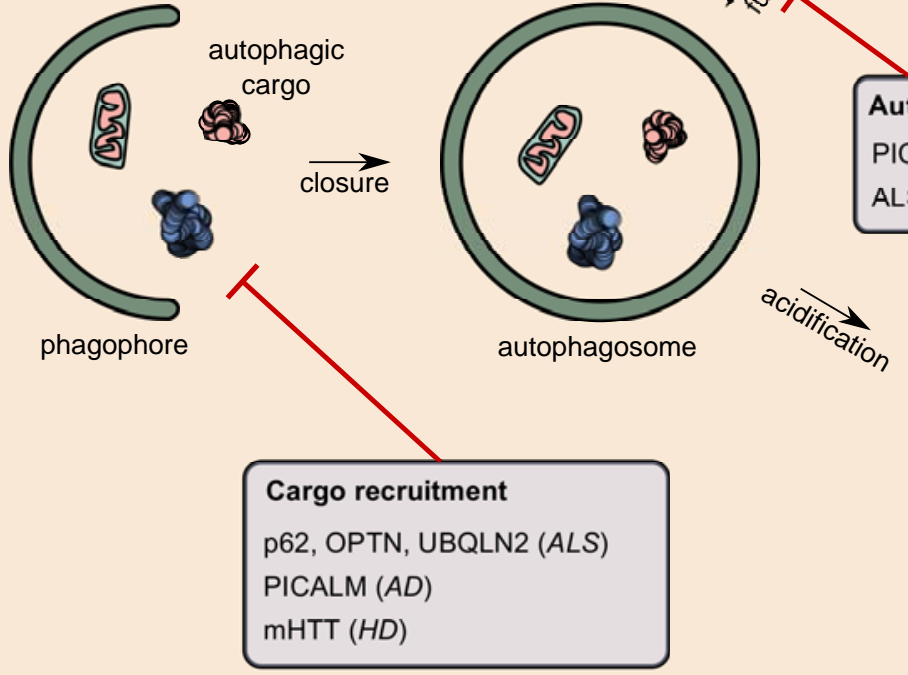

Autolysosome formation PICALM, Tau $(A D)$

ALS2, CHMP2B (ALS)

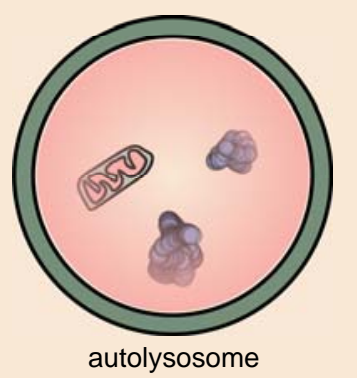




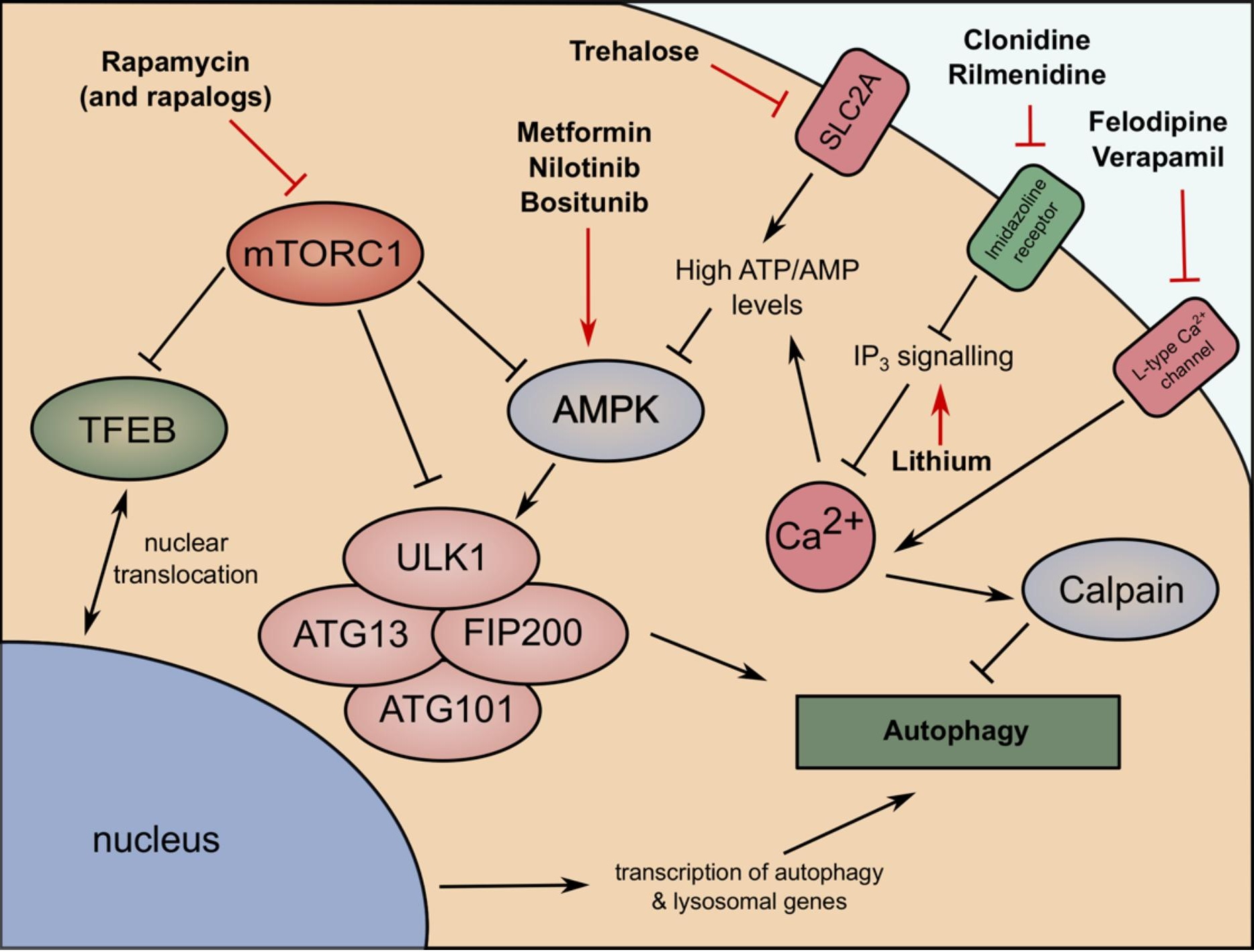

